\title{
Evaluation of plow system performance in long-wall mining method using particle flow code
}

\author{
Mohammadreza Ajamzadeh $^{1} \cdot$ Vahab Sarfarazi $^{1} \cdot$ Hesam Dehghani $^{1}[\mathbb{C}$
}

Received: 18 March 2019/Revised: 14 July 2019/Accepted: 7 August 2019/Published online: 16 August 2019

(C) The Author(s) 2019

\begin{abstract}
The underground or open-pit methods are used for the extraction of mineral resources, each of which is divided into different categories. Coal is one of the mineral resources, which is exploited either by the surface or the underground methods. The long-wall mining is one of the methods for the underground coal mining. In this method, which is a mechanized one, some machines such as the shearer or plow are used for the mining. The coal mine in Parvadeh, Tabas is a mechanized mine that is extracted by the long-wall mining. The modeling with particle flow code software was used in this mine for the evaluation of plow performance using the coal specifications. In this regard, the sample was first calibrated by sampling from the Parvadeh coal mine and performing the uniaxial and Brazilian tests on the model. Then, the modeling was done by constructing the model and using the variables such as the clearance angle and the linear velocity of the plow. After making 28 models for the plow, the best model of the plow was selected based on the maximum force applied to the machine in the $X$ direction. Finally, the results of this study showed that the best plow performance is for a model with the clearance angle of zero and the linear velocity of $9 \mathrm{~mm} / \mathrm{min}$, and the maximum force applied to this model is equal to $39,000 \mathrm{kN}$ in the $\mathrm{X}$ direction.
\end{abstract}

Keywords Plow $\cdot$ Long-wall mining $\cdot$ Particle flow code $\cdot$ Numerical modeling

\section{Introduction}

The open-pit or underground methods are used in mines to extract the minerals. The application of any of these methods depends on the characteristics of the minerals in terms of grade, depth, mineral value, etc. Coal is extracted in both ways. The underground mining for the extraction of this mineral consists of the room and pillar, cut and fill, short-wall mining and long-wall mining methods. The long-wall mining is used when the thickness of the coal

Hesam Dehghani

dehghani@hut.ac.ir

Mohammadreza Ajamzadeh

ajamzadeh@hut.ac.ir

Vahab Sarfarazi

sarfarazi@hut.ac.ir

1 Hamedan University of Technology, Hamedan, Iran layers is significant, but to apply other methods, the thickness of the coal layers is not the main determinant. In the underground mining method, the coal mining is carried out by the shovel, excavator, manual pick hammer, coal cutting machine and even explosives. Coal can be transported by small conveyor belts, electric trains, electric loaders and elevators in the underground.

The long-wall mining is one of the methods used in the coal mines, and sometimes, in metallic or non-metallic mines, and in general, in the layered deposits of low slope and thickness. The long-wall mining approach was initially used in the 17th century in European coal mines and was quickly applied to all coal-producing countries except for the United States. The United States preferred to use the room and pillar method. Today, however, due to the significant growth of this method, including the development of mobile, flexible and shielded conveyors and high-speed, continuous extraction machines, a large number of mines 
are extracted by this method. Two decades ago, in the United States with such geological conditions and huge reserves, it was not thought that there would be a shift from the room and pillar method to the long-wall mining. In 1980, about 5 percent of US coal was extracted by the long-wall mining, which reached 40 percent in 1993 . The development of the long-wall mining in the United States indicates that it is a more economical approach, because economy is primarily thought of in the US mining business.

The long-wall mining is one of the cheapest methods of underground extraction in terms of exploitation among the large-scale methods. In this method, in comparison with any other extraction method, an extra tonnage is obtained for a specific preparation (Stefanko and Bise 1983).

The long-wall mining method is mainly done in three forms: manual, blasting and mechanized methods. In the mechanized method, two plow and drum shearer machines are often used for the grinding operation (Stefanko and Bise 1983).

The plow is a device equipped with multiple blades which is in contact with the coal layer while moving along the field, and thus, every time, it scratches a piece of coal from the face at a depth of 5-18 cm and transports to the conveyor behind the machine. The machine is mounted on a chain conveyor and the blade moves through the crane cable. This machine was first used in Germany in 1940.

The plows are generally used in special geological conditions and require little investment and maintenance costs. The speed of plow movement varies from 1 to $4 \mathrm{~m} / \mathrm{s}$ and the thickness of the layer used by the plow ranges from 0.6 to $1.8 \mathrm{~m}$. The hook, sliding and impact plows are the three main types of plow, which are commonly used (Stefanko and Bise 1983). Figure 1 shows a plow in operation.

Among the most important goals of mechanization are the reduced operational costs, increased productivity, faster development, faster mining, more safe mining, removal of small faces and, in other words, centralization of extraction operation, achieving more production rates in each shifts, mining with fewer staff, and more efficient selection of employees (Ataei et al. 2009).

In many cases, to investigate the effect of different factors on a project, many expenses should be incurred, which is economically costly and time-consuming and, sometimes, practically not feasible. In this situation, the simulation methods and performance prediction can be effectively used to reduce the time and cost. One of these methods is the numerical modeling.

Whittaker and Guppy (1970) investigated the highspeed plowing with a special source for the constant cutting principle. In this study, the variable parameters are plowing speed, conveyor belt speed, and extraction depth and conveyor capacity. The results show that one-way plow can be more useful, because it can be used at higher speed without the need to reduce the shear depth (Whittaker and Guppy 1970).

According to the importance of the coal production, many researchers try to investigate the various aspects of this subject (Cheng et al. 2015; Hejmanowski 2015; Ju et al. 2019; Fan and Ma 2018; Wirth et al. 2018; Zhuravlev and Porokhnov 2019).

Osterman (1974) compared the shearer and plow according to the seam properties, equipment, advance rate, etc. for the German mines. Merritt (1989) examined the thin-seam plowing in the United States in terms of economy. Smith (1972) conducted the numerical modeling for the optimum rate of plowing and the speed of conveyor belt and plow for the cutting of a two-sided plow. Paschedag (2011) examined the technology, history and current state of the plow in industry. In this study, the improvement of the plow system including: increasing the height of cutting up to 2 meters, increasing automation capability, constant

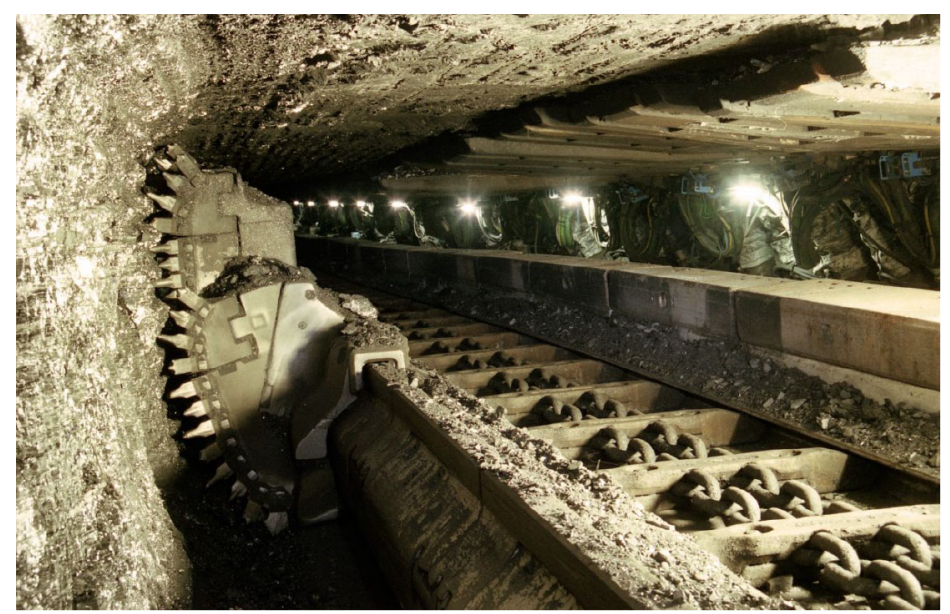

Fig. 1 A plow in operation 
speed of $3.6 \mathrm{~m} / \mathrm{s}$ was investigated. Stopa (2011) explained the plowing technique in the Bogdanka coal mine, Poland. In this study, the author's experiences were brought to the mine, and it was discussed to purchase the second system in the mine. Xianguang Tang (2011) described the operational experiences of the automatic plow system in the Tiefa mine, China. Tor (2011) described the past experiences and future expectations with regard to the application of plow technology in the Polish Jastrzebska Spolka Weglowa mine. This paper was related to the use of a plow in thin layers. Myszkowski (2011) investigated the optimization of the plow system efficiency through a new precise design and expanding the scope of long-wall operation. This study dealt with the problems of increasing the production ranging from technical, approach and organizational problems. Voss (2011) examined the plow operation on the long-wall mining under different geological conditions. In this study, the experiences of German Company in high production were stated. Bauckmann and Myszkowski (2011) described the operational experiences for the plow system in the Pinnacle mine in the United States. Kurtobashev (2011) examined the contemporary plow technology in Russia. Matula (2011) examined the plow equipment used in the OKD mine, Czech Republic. Philipp (2011) presented a paper titled "Chains_-boon or bane for modern plow technology?" In this paper, the importance of actual production and engineering skills in some manufacturers of equipment and chain manufacturers were discussed, which are integrated in the mining knowledge. Chagowski (2011) examined the performance of automation, control and power supply systems for the high-performance plow systems based on an example of the Bogdanka coal mine. Lee and Choi (2011) undertook a research to analyze cutting power of a cutter disk according to joint pattern considering various joint angles, orientations, and spacing in jointed rock mass models using PFC2D Software. Sun (2011) simulated the rock grinding process by cutting disk of a tunnel boring machine (TBM) using PFC2D Software. Moon and Oh (2012) used discrete element method (PFC2D) to examine the optimal conditions for cutting a rock using hard-rock TBMs. Lee and Choi (2013) used a numerical software (PFC3D) to study the shear behavior of a cutting disk on rock. In another research, Choi and Lee (2015) considered shear behavior of rock by a single cutting disk using PFC3D.

Using the experimental tests and modeling efforts by PFC2D, Haeri et al. (2016) investigated the impacts of shear strength of rock on hard shear failure. Haeri and Sarfarazi (2016) used PFC to model shear failure of cement26. Sarfarazi et al. $(2017 \mathrm{a}, \mathrm{b})$ investigated the shear behavior of discontinuous joints under high normal loading using PFC2D Software. In another research, Sarfarazi et al. (2017a, b) utilized PFC2D to model and investigate failure mechanism of Brazilian disks with multiple parallel joints. Yang et al. (2018) used PFC to consider mechanical failure behaviors of bored granite samples at elevated temperature. Ajamzadeh et al. (2018) investigated the parameter affecting the coal calibration in PFC software. In this study, the effect of failure angle, friction angle, accumulation coefficient and disc spacing was investigated. The innovation of this work is to study the effect of plow angle on the failure mechanism of rock coal in an experimental and numerical manner.

\section{Methodology}

In the numerical modeling methods, different methods may be used depending on the type of model, such as finite element method, finite volume method, finite difference method, spectral element method, and so on. In this paper, the PFC 2D vol. 5 software was used for modeling which performed the modeling by the discrete element method. The flowchart in Fig. 2 shows the process of conducting the research. In this research, two parameters of linear velocity and clearance angle of the plow are used as the variables for modeling.

\subsection{Pfc model}

The PFC programs (PFC2D and PFC3D) provide a general purpose, discrete-element modeling framework that includes a computational engine and a graphical user interface. A particular instance of the distinct-element model is referred to as a PFC model, which refers to both the $2 \mathrm{D}$ and $3 \mathrm{D}$ models. The PFC model simulates the movement and interaction of many finite-sized particles. The particles are rigid bodies with finite mass that move independently of one another and can both be translated and rotated. The particles interact at pair-wise contacts by means of an internal force and moment. Contact mechanics is embodied in particle-interaction laws that update the internal forces and moments. The time evolution of this system is computed via the discrete-element method, which provides an explicit dynamic solution to Newton's laws of motion. The PFC model provides a synthetic material consisting of an assembly of rigid grains that interact at contacts and includes both granular and bonded materials (Potyondy and Cundall 2004).

The flat-joint model provides the macroscopic behavior of a finite-size, linear elastic and either bonded or frictional interface that may sustain partial damage (Fig. 3) (Potyondy 2015). 


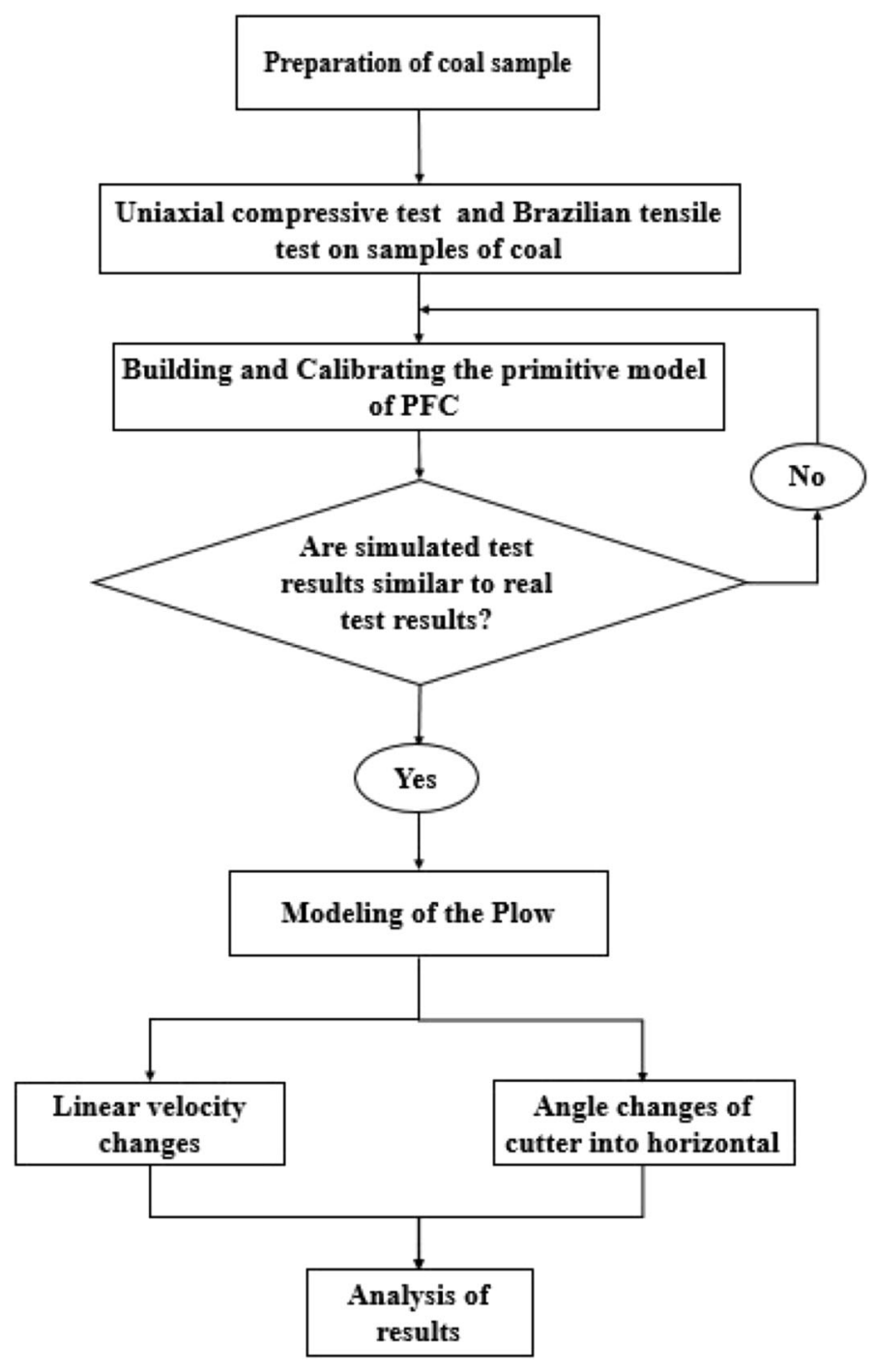

Fig. 2 Schematic chart of research performing

\subsection{Model generation}

In the present research, in order to build the models, the coal samples were collected from the Parvadeh Coal Mine (which is a mechanized mine) before being subjected to the uniaxial and Brazilian tests. Then, considering the obtained results, the built models were calibrated.

\subsubsection{Data gathering}

Given that the present research required real data, Parvadeh Coal Mine (Tabas, Iran, the only mechanized coal mine in Iran) was selected as the study area.

Extending over an area of about 1200 square kilometers, Parvadeh District is located $70 \mathrm{~km}$ to the south of Tabas Township, Iran. Coking coal reserve of the area is the largest across the country and estimated at 1.1 billion tons. Considering the quality and quantity of the reserves across
Parvadeh District, most of the exploratory activities and mining plans across Tabas are dedicated to this district. The mean height of coal-bearing area in Parvadeh is 850 from the mean sea level.

A total of 29 coal layers have been identified in this area; these have been classified into the general classes of A-F. The most important coal layers with minable thickness $(>0.4 \mathrm{~m})$ include $\mathrm{C} 1, \mathrm{C} 2, \mathrm{~B} 1, \mathrm{~B} 2, \mathrm{E}$, and $\mathrm{D}$, among which the $\mathrm{C} 1$ exhibits the largest extension and continuity across the region and is well minable (Tabas coal mine 1995).

In this mine, the mining operation is performed via fullmechanized retreating longwall method. A total of 27 stopes were designed for this mine, from which a total of 29 million tons of raw coal will be mined. As of now, the stope $\mathrm{W} 1$ in this mine is actively mining (Tabas coal mine 1995). 

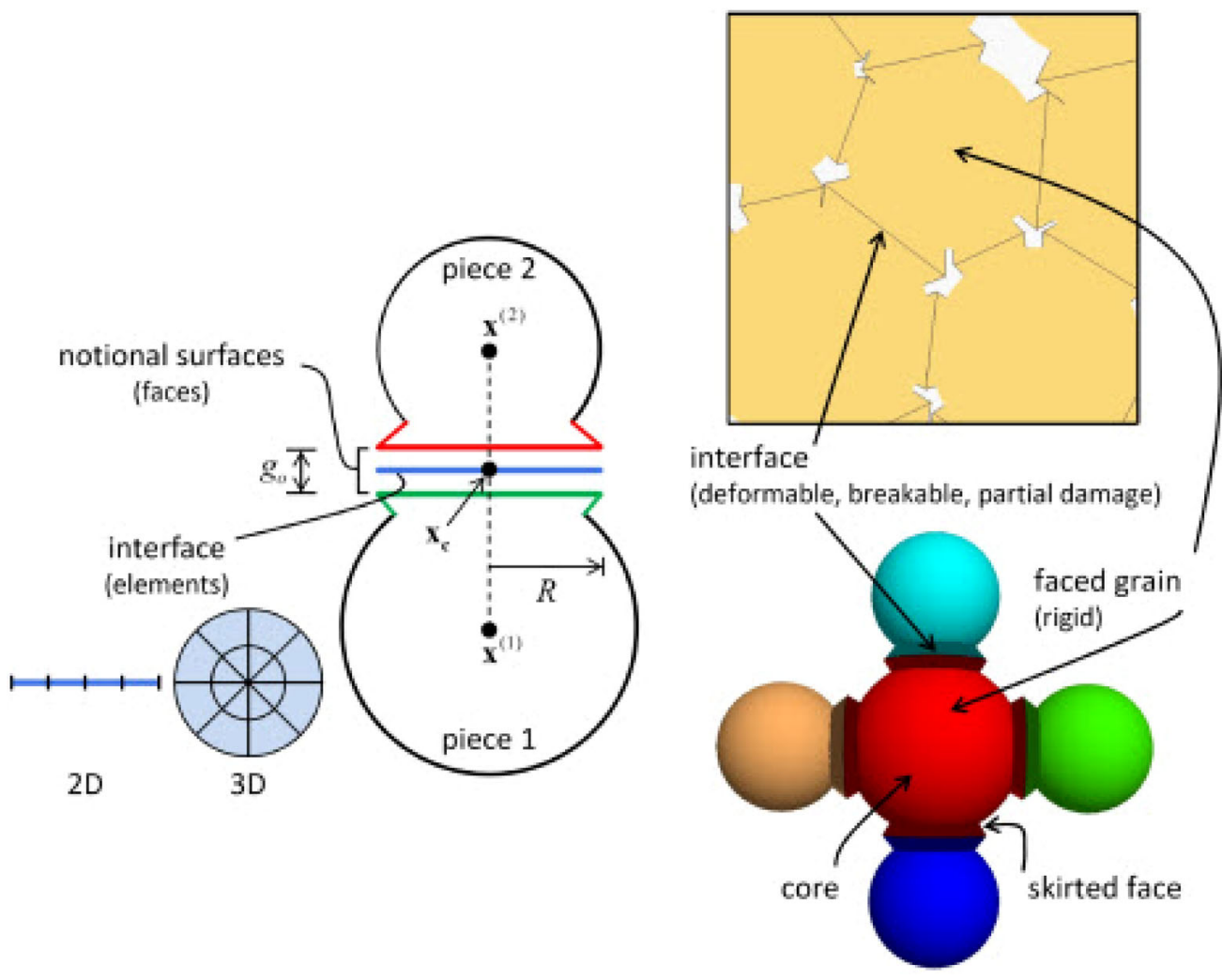

Fig. 3 Flat-joint contact (left) and flat-jointed material (right) (Potyondy 2015)

\subsubsection{Model calibration}

In order to undertake these tests, we began with preparing a sample of Parvadeh Coal Mine (Tabas, Iran). The sample was then sent to the rock mechanics laboratory for the uniaxial compressive strength and indirect tensile tests, and the results are presented in Table 1.

In order to calibrate the coal in PFC Software, considering the failure curve and the values obtained from uniaxial strength and Brazilian tests on the samples, the uniaxial and Brazilian tests were simulated.

To perform the uniaxial and Brazilian tests in PFC Software, one should begin with creating an initial model and making it equilibrated. Afterwards, the developed model can be subjected to loading using the codes for the uniaxial and Brazilian tests. Table 2 reports the micro-parameters used for constructing the base sample along with their values.

Once the initial model was loaded and the uniaxial and Brazilian tests were performed, the failure mode and failure curve were compared to those obtained from the real samples tested in the laboratory. If the failure mode and related values are similar to those of the real sample, the model is considered as ready for the final modeling stage; otherwise, the initial model should be regenerated followed by another round of loading and so on. Figures 4 and 5 compare the results of uniaxial and Brazilian tests in PFC Software with those of real tests.

Furthermore, Table 3 presents the numerical results of actual tests as compared with those of PFC Software.

\subsubsection{Construction of final model}

After calibrating the desired model, the basic model is constructed for plow modeling using the obtained results. Accordingly, an area of $108 \mathrm{~mm} \times 54 \mathrm{~mm}$ was selected as the initial area. Then, by removing the upper part, the conditions for inserting the cutter were provided. Figure 6 shows an example of the generated area.

Table 1 Compressive and tensile strength tests results

\begin{tabular}{llllll}
\hline Tensile strength $(\mathrm{MPa})$ & Uniaxial compressive strength $(\mathrm{MPa})$ & Failure surface angle $\left(^{\circ}\right)$ & Surface $\left(\mathrm{mm}^{2}\right)$ & Length $(\mathrm{mm})$ & Diameter $(\mathrm{mm})$ \\
\hline- & 3.1 & 55 & 2409.3 & 108 & 55.4 \\
0.62 & - & - & 2409.3 & 35 & 55.4 \\
\hline
\end{tabular}


Table 2 Micro properties used for model calibration

\begin{tabular}{llllll}
\hline No. & Micro properties & Value & No. & Micro properties & Value \\
\hline 1 & Particle distance & $0.5 \mathrm{~mm}$ & 11 & Model height & $108 \mathrm{~mm}$ \\
2 & Elastic modulus (yang) & $190 \mathrm{MPa}$ & 12 & Model width & $54 \mathrm{~mm}$ \\
3 & K-ratio & 2 & 13 & Expansion coefficient & 0.7 \\
4 & Friction coefficient & 0.5 & 14 & Accumulation factor & $2500 \mathrm{~N} / \mathrm{cm}^{2}$ \\
5 & Tensile strength & $0.85 \mathrm{MPa}$ & 15 & Density & $0.6 \mathrm{~mm}$ \\
6 & Tensile strength standard deviation & $0.001 \mathrm{MPa}$ & 16 & Minimum diameter of particles \\
7 & Compressive strength & $0.7 \mathrm{MPa}$ & 17 & Maximum diameter of particles & $1.2 \mathrm{~mm}$ \\
8 & Compressive strength standard deviation & $0.1 \mathrm{MPa}$ & 18 & Material pressure & $0.1 \mathrm{MPa}$ \\
9 & Friction angle & $20^{\circ}$ & 19 & Material pressure changes & 0.01 \\
10 & Porosity & 0.08 & & & \\
\hline
\end{tabular}

(a)

(c)
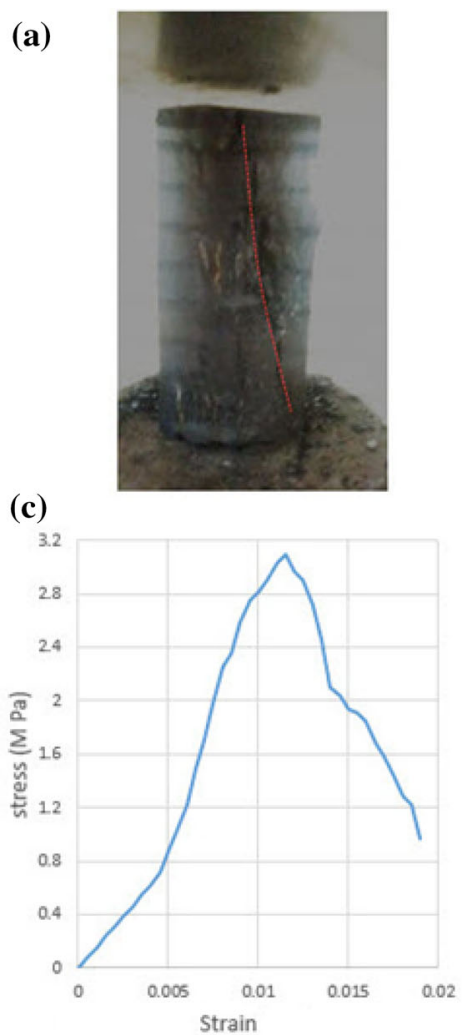

(b)

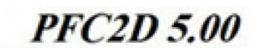

O2015 Itasea Consulting Group, Inc. mechanical step : 92921

Ball group Any

Balls (8106)

CG_Flat Jointed2D-SD1 CG_ParalleiBonded2D-SD DFN group Any

Fractures (8366)

FJ-shearFail

FJ-tenFa

PB-tenFail

Wall name

Facets (2)

dcBottom

deTop

(d)

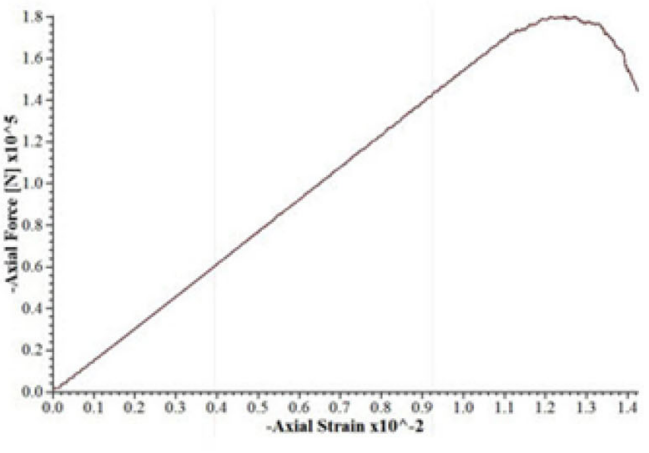

Fig. 4 Failure pattern in a experimental test, $\mathbf{b}$ numerical simulation, $\mathbf{c}$ stress-strain curve in experimental test, $\mathbf{d}$ stress-strain curve in numerical test

In this research, a $20 \mathrm{~mm}$ long area (line) was used as the cutting pick element of the plow. This area cut the model width, and an example is shown in Fig. 6.

For the plow modeling, two parameters of linear velocity and clearance angle were selected as the variables. The linear velocities were considered as 3, 6, 9 and $12 \mathrm{~mm} /$ min and the clearance angles were $0^{\circ}, 15^{\circ}, 30^{\circ}, 45^{\circ}, 60^{\circ}$, $75^{\circ}$ and $90^{\circ}$.

\section{Discussion}

In this section, we examine the results of plow modeling using PFC 2D v. 5 software. The modeling is done using the flat-jointed model in this software. Here, the results for each angle are checked for different linear velocities.

For the modeling of the shearer, 28 models were developed in this study. Then, the models were classified based on the clearance angle and linear velocity. These models are presented in Table 4. 
(a)

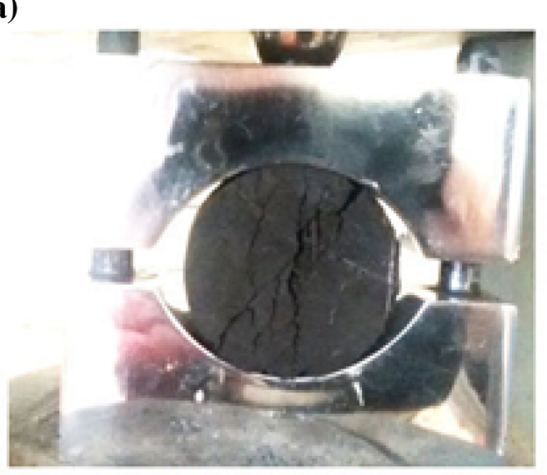

(c)

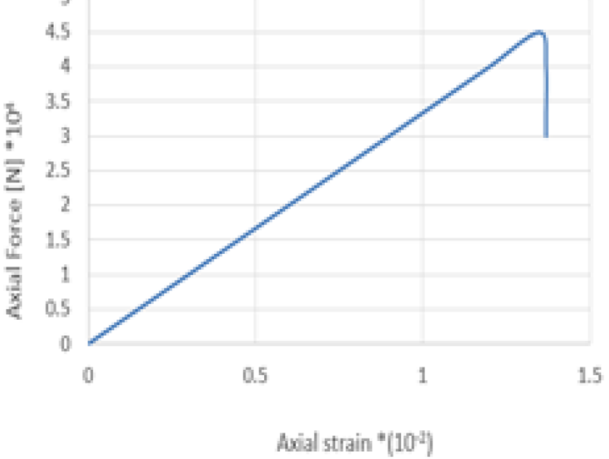

(b)
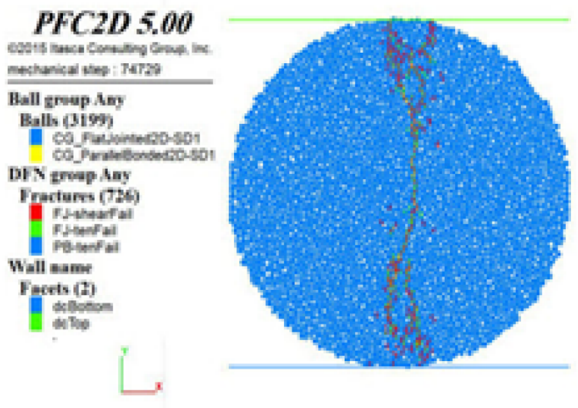

(d)

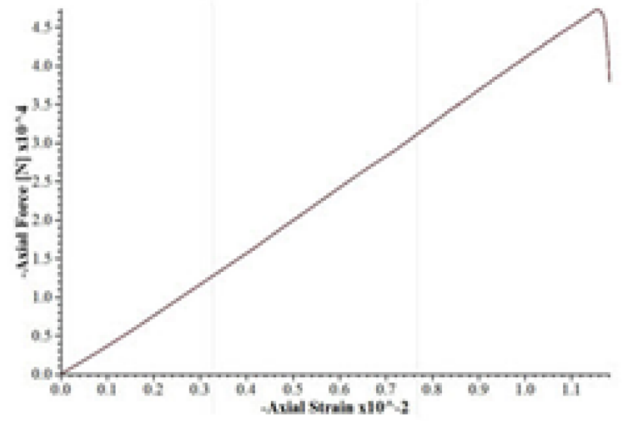

Fig. 5 Failure pattern in a experimental test, $\mathbf{b}$ numerical simulation, $\mathbf{c}$ stress-strain curve in experimental test, $\mathbf{d}$ axial force versus axial strain in numerical model

Table 3 Results of compressive strength and tensile strength rendered by experimental test and numerical simulation

\begin{tabular}{lll}
\hline Value & Tensile strength (MPa) & Compressive strength (MPa) \\
\hline Real value & 0.62 & 3.1 \\
Modeling value & 0.83 & 3.3
\end{tabular}

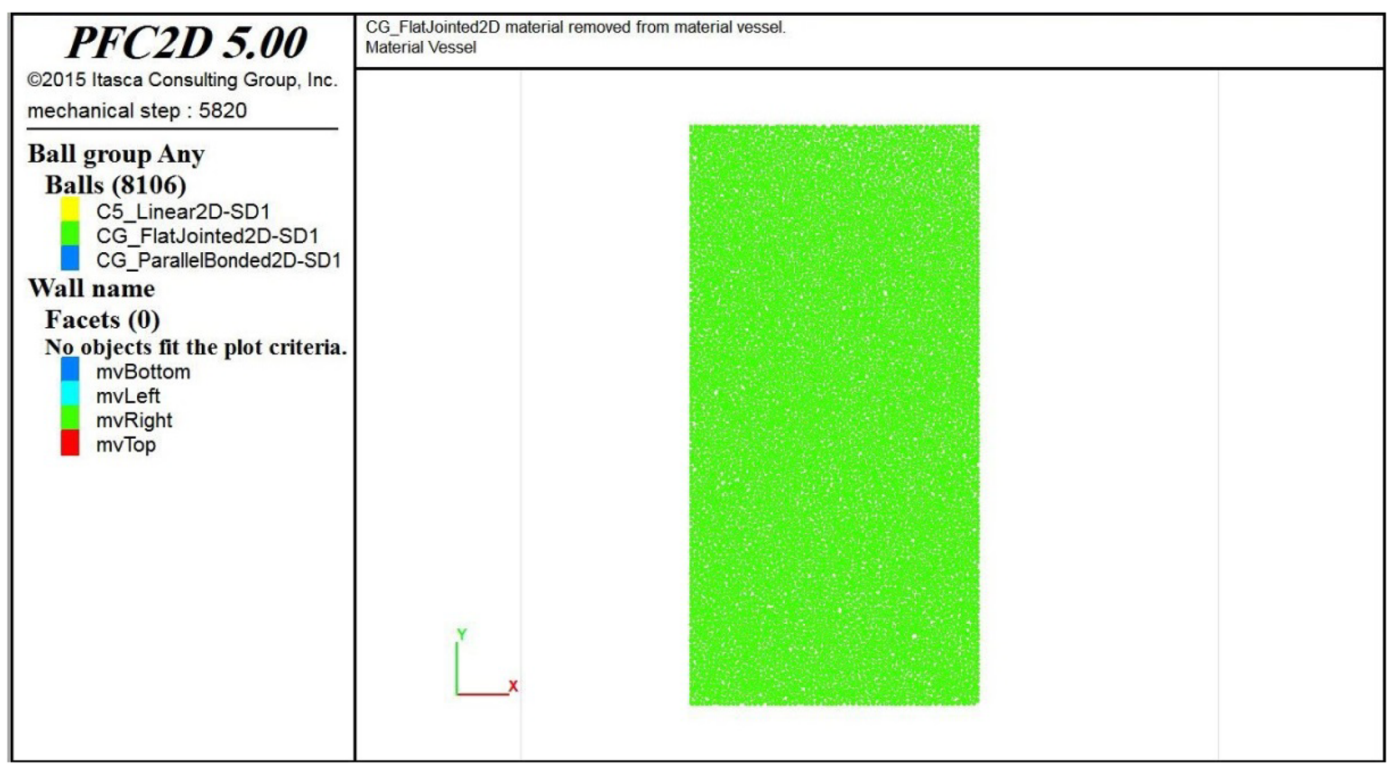

Fig. 6 Numerical model for Shearer test simulation 
Table 4 Specification of plow

\begin{tabular}{|c|c|c|c|c|c|}
\hline Model & $\begin{array}{l}\text { Angle changes of cutter } \\
\text { into horizontal }\left({ }^{\circ}\right)\end{array}$ & $\begin{array}{l}\text { Linear velocity } \\
\text { changes }(\mathrm{mm} / \mathrm{min})\end{array}$ & Model & $\begin{array}{l}\text { Angle changes of cutter } \\
\text { into horizontal }\left(^{\circ}\right)\end{array}$ & $\begin{array}{l}\text { Linear velocity } \\
\text { changes }(\mathrm{mm} / \mathrm{min})\end{array}$ \\
\hline Model 1 & 0 & 3 & Model 15 & 45 & 9 \\
\hline Model 2 & 0 & 6 & Model 16 & 45 & 12 \\
\hline Model 3 & 0 & 9 & Model 17 & 60 & 3 \\
\hline Model 4 & 0 & 12 & Model 18 & 60 & 6 \\
\hline Model 5 & 15 & 3 & Model 19 & 60 & 9 \\
\hline Model 6 & 15 & 6 & Model 20 & 60 & 12 \\
\hline Model 7 & 15 & 9 & Model 21 & 75 & 3 \\
\hline Model 8 & 15 & 12 & Model 22 & 75 & 6 \\
\hline Model 9 & 30 & 3 & Model 23 & 75 & 9 \\
\hline Model 10 & 30 & 6 & Model 24 & 75 & 12 \\
\hline Model 11 & 30 & 9 & Model 25 & 90 & 3 \\
\hline Model 12 & 30 & 12 & Model 26 & 90 & 6 \\
\hline Model 13 & 45 & 3 & Model 27 & 90 & 9 \\
\hline Model 14 & 45 & 6 & Model 28 & 90 & 12 \\
\hline
\end{tabular}

The results of the plow model with a zero-degree angle at the velocities of 3 and $6 \mathrm{~mm} / \mathrm{min}$ are presented in Fig. 7, and the results of the plow model with the velocities of 9 and $12 \mathrm{~mm} / \mathrm{min}$ are shown in Fig. 8 .

Finding the maximum force applied to the plow in each of the above models shows that the lowest force is 38,000 $\mathrm{kN}$ for model 1 (at $3 \mathrm{~mm} / \mathrm{min}$ ) and the highest value is $59,000 \mathrm{kN}$ for model 4 (at $12 \mathrm{~mm} / \mathrm{min}$ ). In models 3 and 2, the maximum forces applied to the plow are 39,000 and $43,000 \mathrm{kN}$, respectively. According to the comparison between the two models 1 and 3 and given the number of joints generated in each model, which are approximately identical, according to the higher speed of the model 3 $(9 \mathrm{~mm} / \mathrm{min})$ and the higher production rate, the higher applied force of this model can be neglected, and it was considered as the best sample among the four models with the zero angle to the horizon.

The results of the plow model with a $15^{\circ}$ angle at the velocities of 3 and $6 \mathrm{~mm} / \mathrm{min}$ are presented in Fig. 9, and the results of the plow model with the velocities of 9 and $12 \mathrm{~mm} / \mathrm{min}$ are shown in Fig. 10.

Comparing the models 5 to 8 and observing the maximum force applied to each model, the best model can be considered as the model $7(9 \mathrm{~mm} / \mathrm{min})$. In this model, the maximum force applied to the plow is $43,000 \mathrm{kN}$ and the number of created cracks is the lowest after model 6 , followed by models 8,5 , and 6 , respectively.

The results of the plow model with a $30^{\circ}$ angle at the velocities of 3 and $6 \mathrm{~mm} / \mathrm{min}$ are presented in Fig. 11, and the results of the plow model with the velocities of 9 and $12 \mathrm{~mm} / \mathrm{min}$ are shown in Fig. 12.

Comparing the results of models $9-12$, the best result is obtained from model $9(3 \mathrm{~mm} / \mathrm{min})$. In this model, the
$45,000 \mathrm{kN}$ is the highest amount of applied force, which is less than the rest of the models. After this model, the models with the velocities of 10,12 and 11 have the lowest value, respectively.

The results of the plow model with a $45^{\circ}$ angle at the velocities of 3 and $6 \mathrm{~mm} / \mathrm{min}$ are presented in Fig. 13, and the results of the plow model with the velocities of 9 and $12 \mathrm{~mm} / \mathrm{min}$ are shown in Fig. 14.

The best model based on the results of these models at 45 degrees is the model 13, with the maximum applied force equal to $55,000 \mathrm{kN}$. The number of cracks is also the smallest one. The models 15, 14 and 16 also have better results after this model, respectively.

The results of the plow model with a $60^{\circ}$ angle at the velocities of 3 and $6 \mathrm{~mm} / \mathrm{min}$ are presented in Fig. 15, and the results of the plow model with the velocities of 9 and $12 \mathrm{~mm} / \mathrm{min}$ are shown in Fig. 16.

Among these models, the model 17 is also the best one. In other models, the maximum force applied to the plow is significantly increased, which can be due to the increase in the angle and causes more plow contact with the material. After the model 17, the models 18, 19 and 20 have the lowest values, respectively.

The results of the plow model with a $75^{\circ}$ angle at the velocities of 3 and $6 \mathrm{~mm} / \mathrm{min}$ are presented in Fig. 17, and the results of the plow model with the velocities of 9 and $12 \mathrm{~mm} / \mathrm{min}$ are shown in Fig. 18.

In these models (models 21 to 24), a very large increase in the force applied on the plow can be observed, which is due to the increase in the angle of plow to the horizon, and according to the previous results, the increasing trend of the amount of force applied to the plow can be seen with increasing the angle of plow. Among these four models, the 

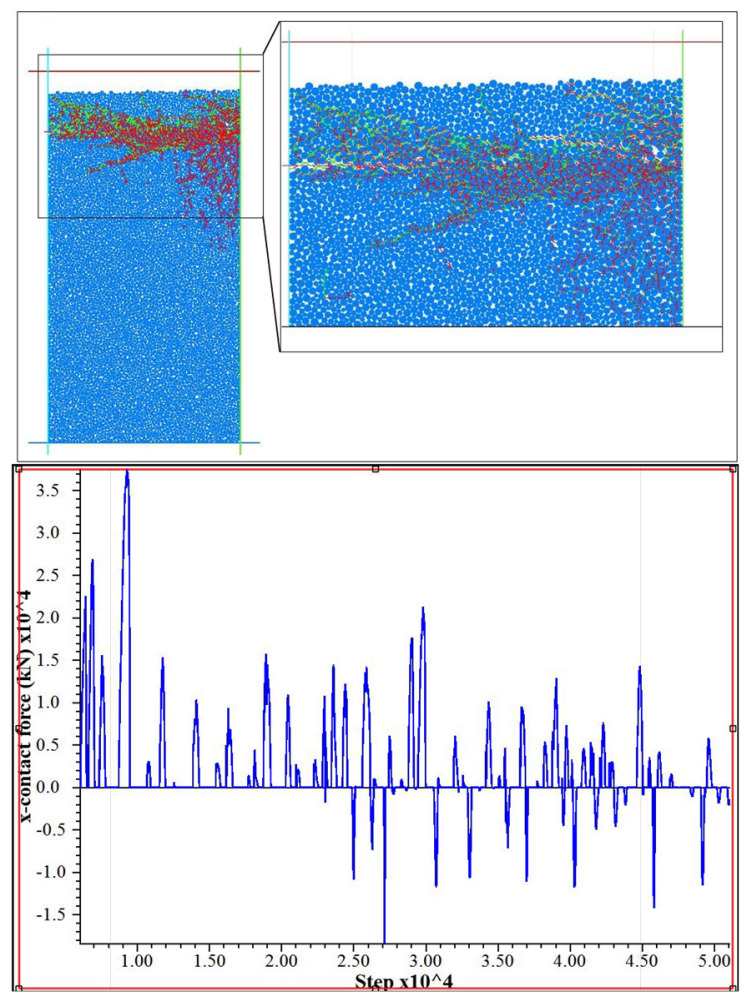

(a)
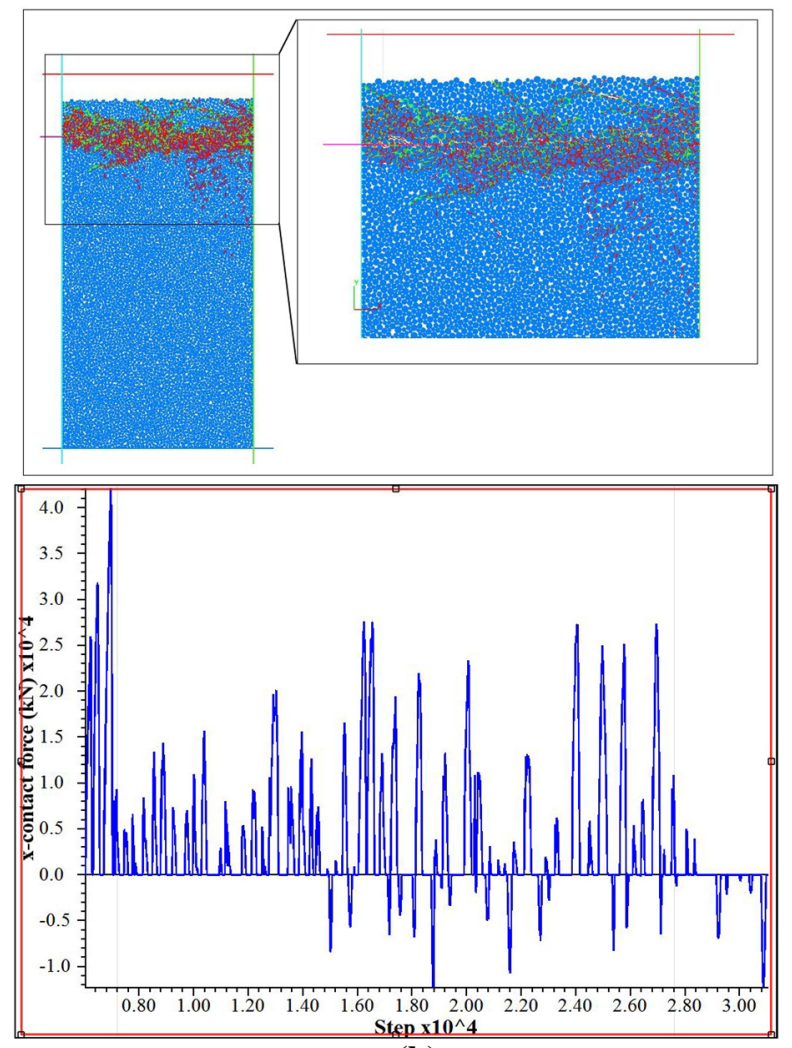

(b)

Fig. 7 Results of plow model with zero-degree angle: a Model 1, b Model 2

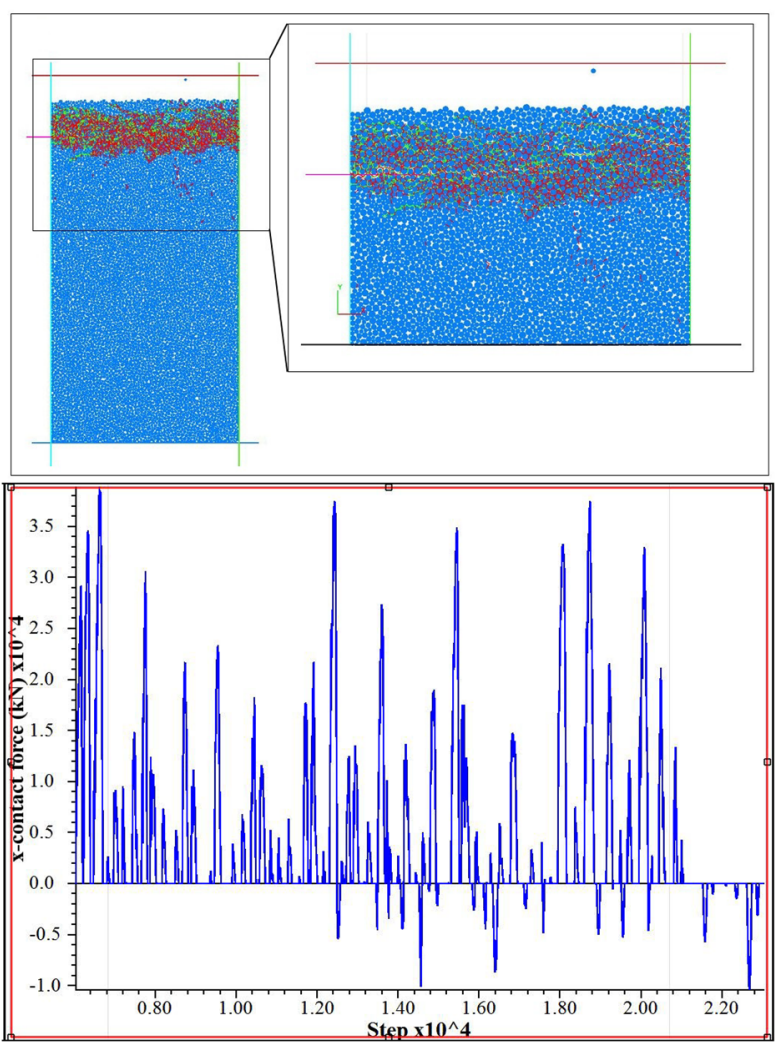

(a)
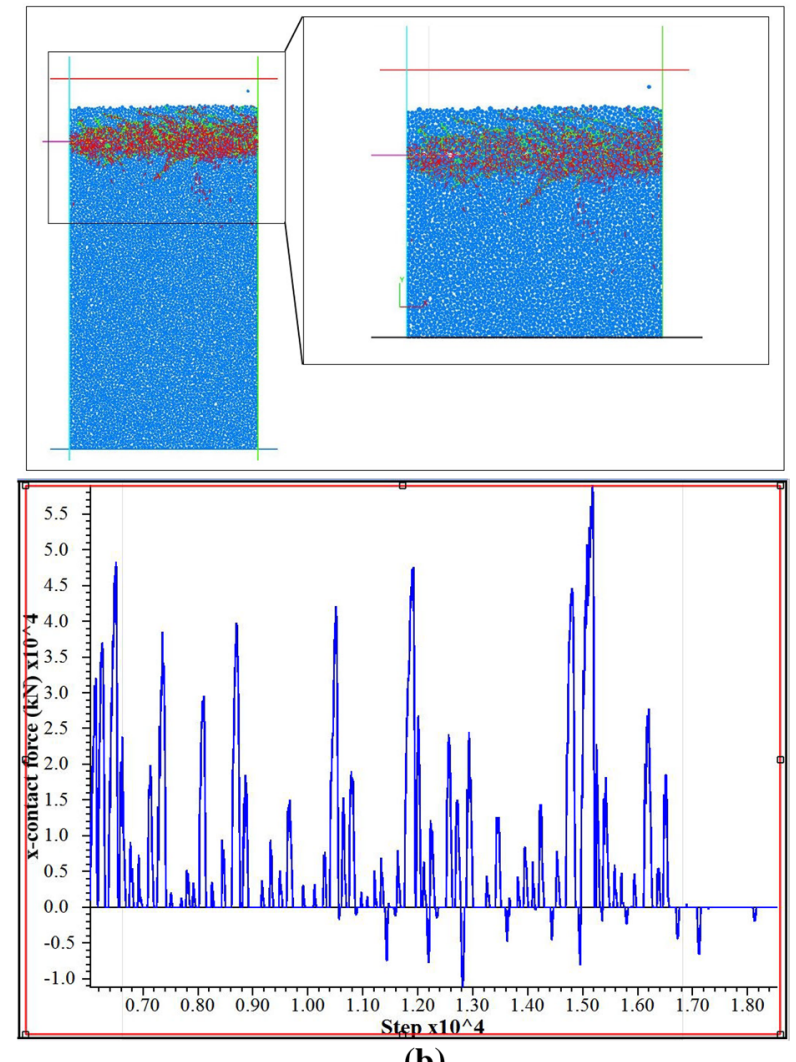

(b)

Fig. 8 Results of plow model with zero-degree angle: a Model 3, b Model 4 


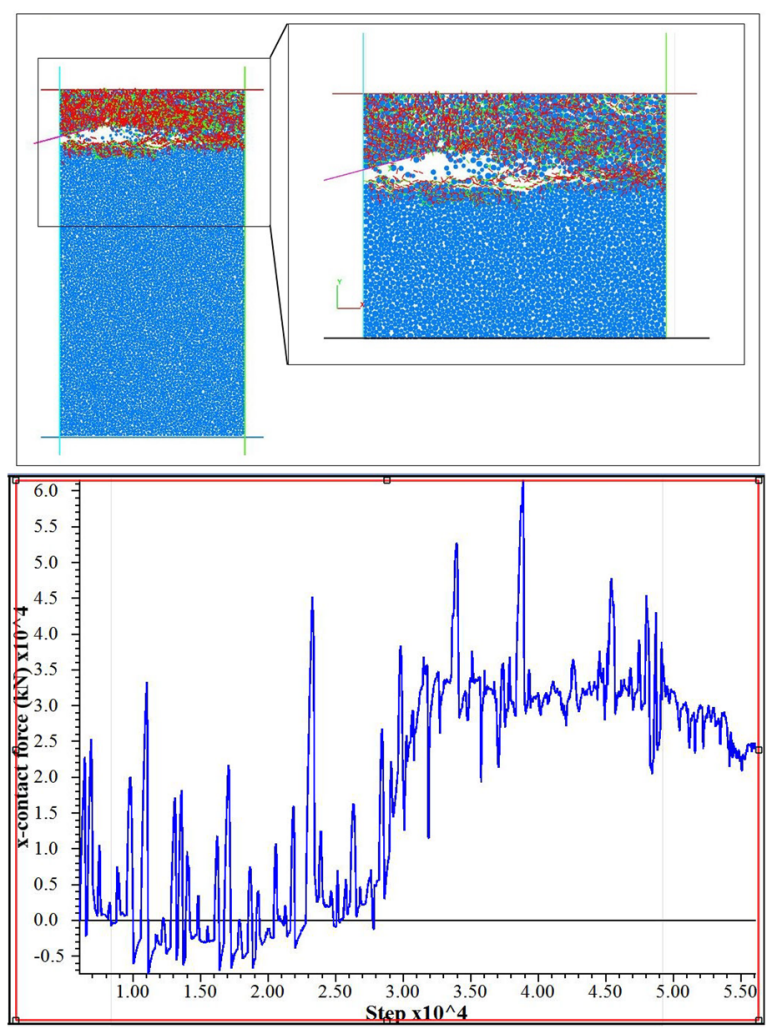

(a)

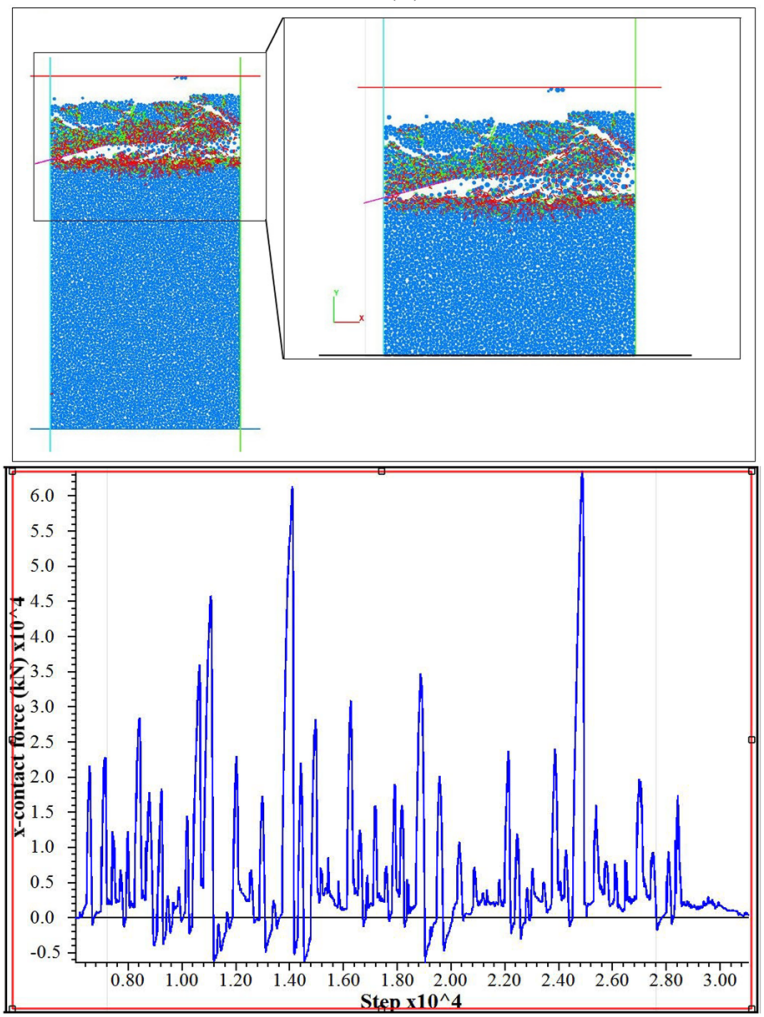

(b)

Fig. 9 Results of plow model with zero-degree angle: a Model 5, b Model 6

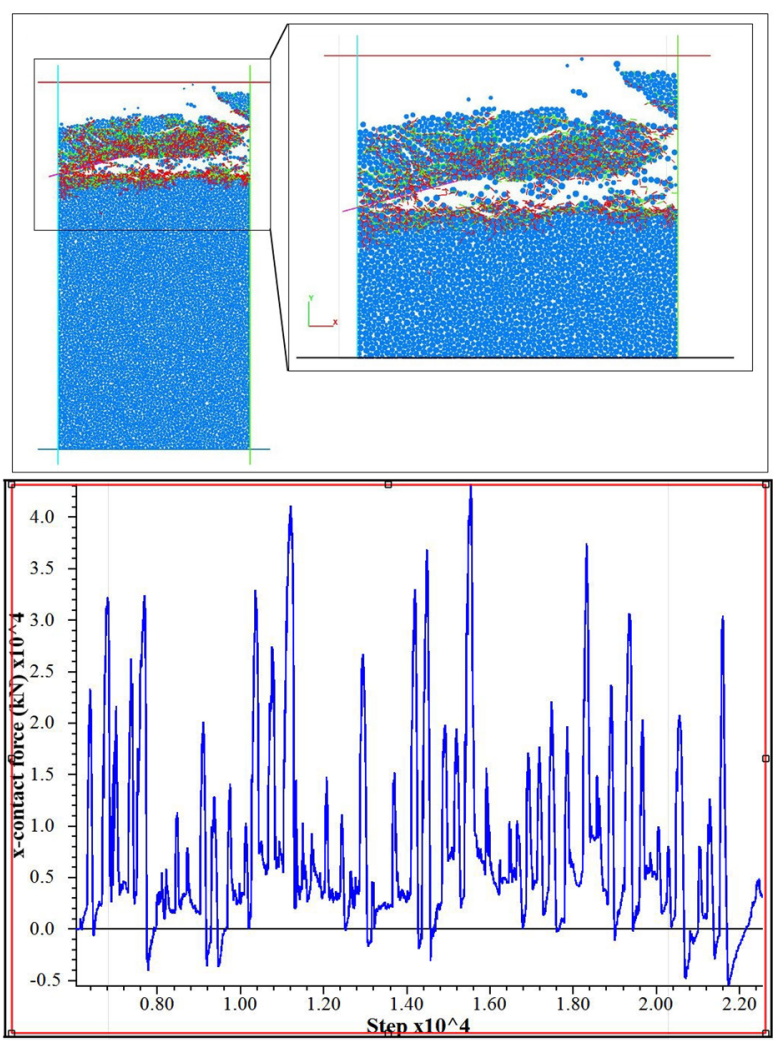

(a)
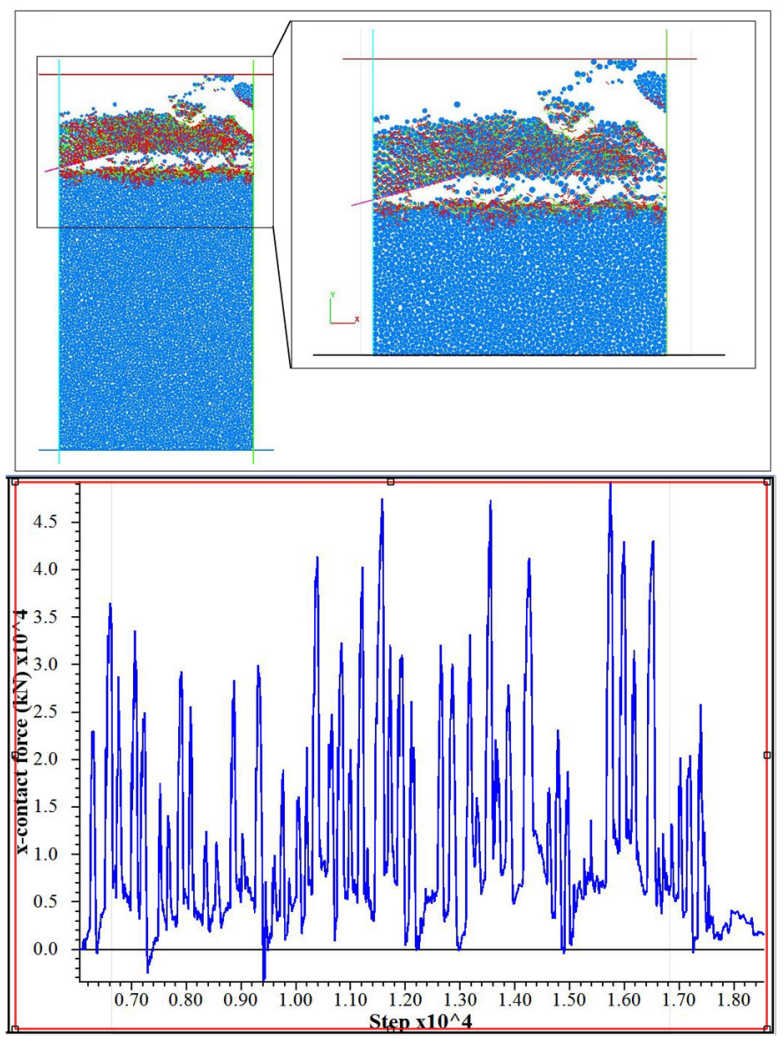

(b)

Fig. 10 Results of plow model with zero-degree angle: a Model 7, b Model 8 

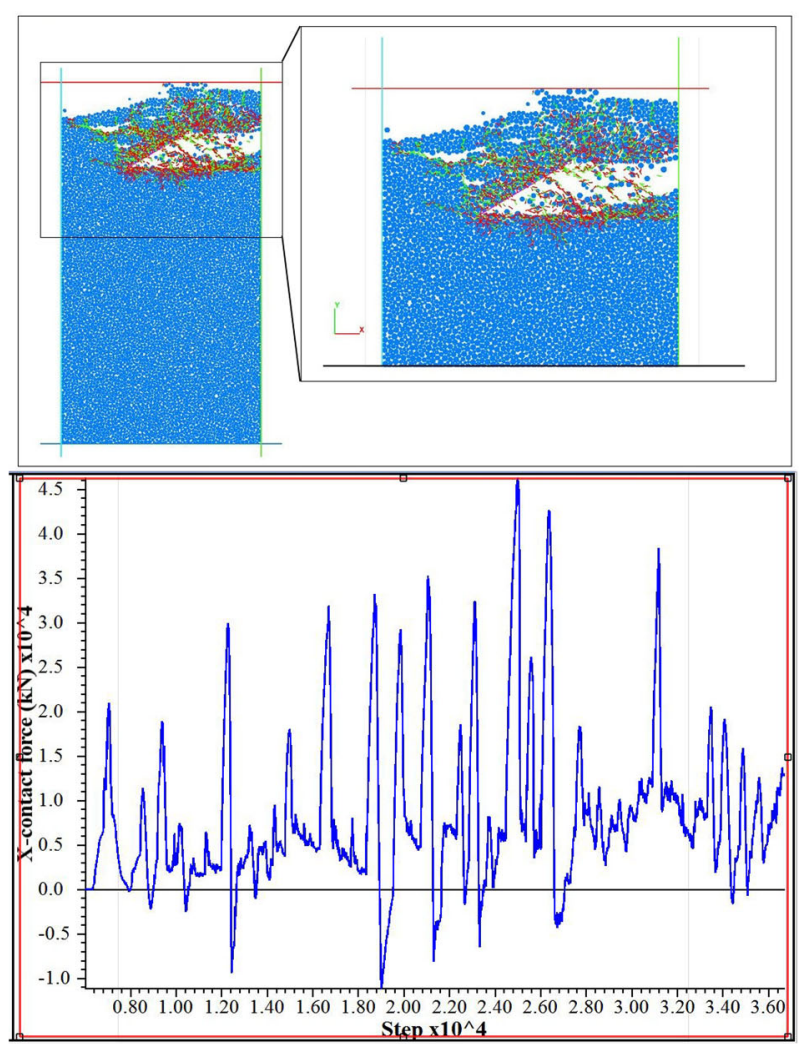

(a)
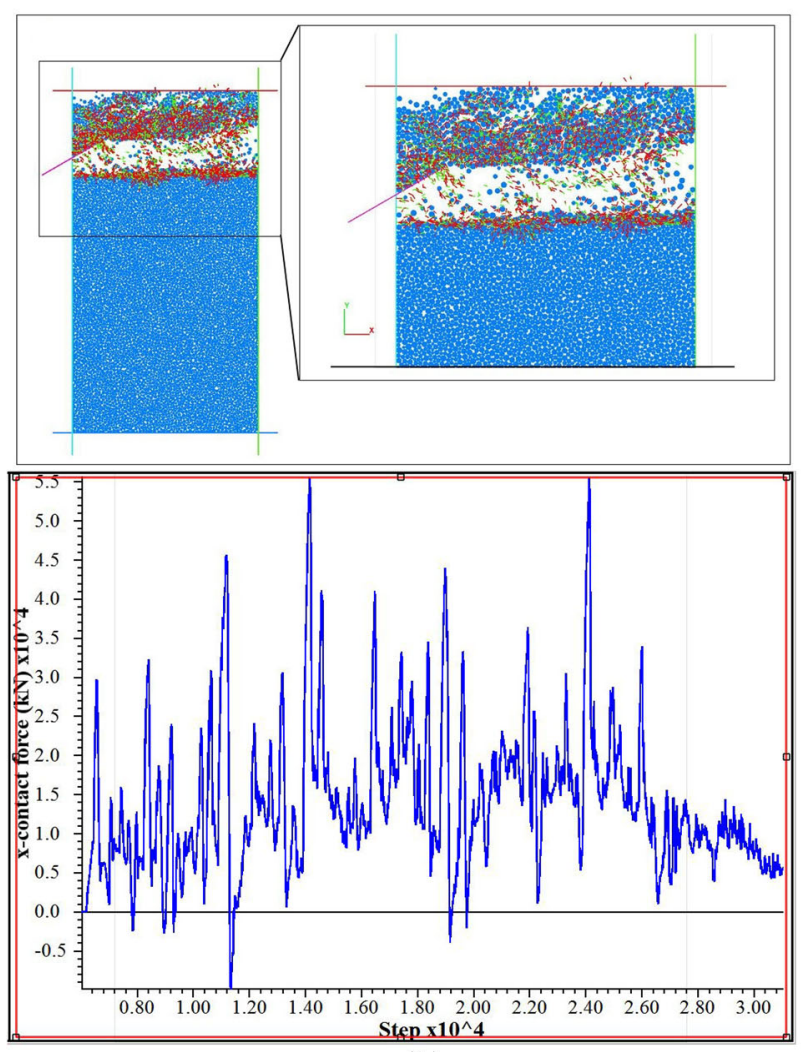

(b)

Fig. 11 Results of plow model with zero-degree angle: a Model 9, b Model 10

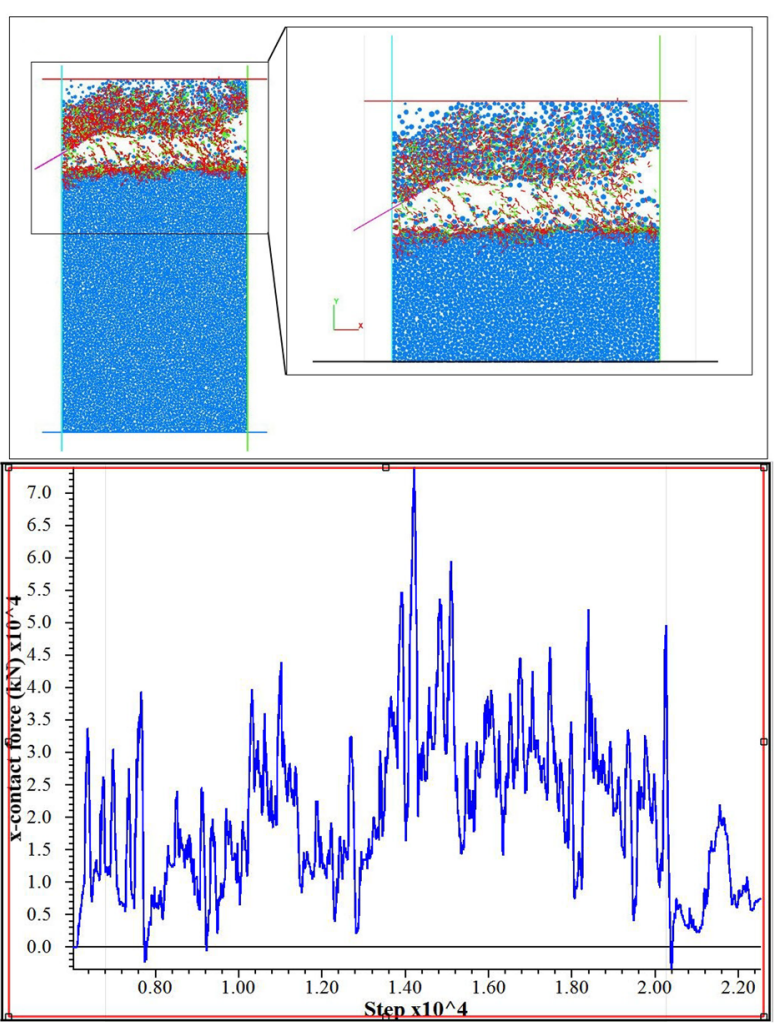

(a)

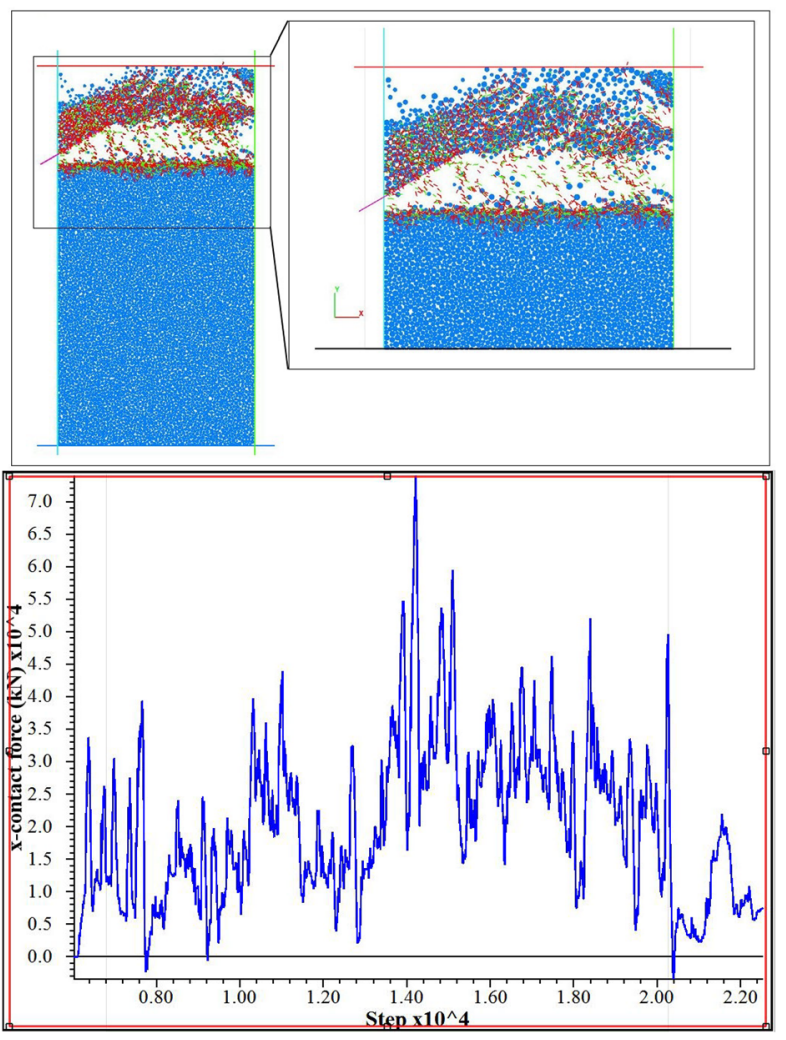

(b)

Fig. 12 Results of plow model with zero-degree angle: a Model 11, b Model 12 


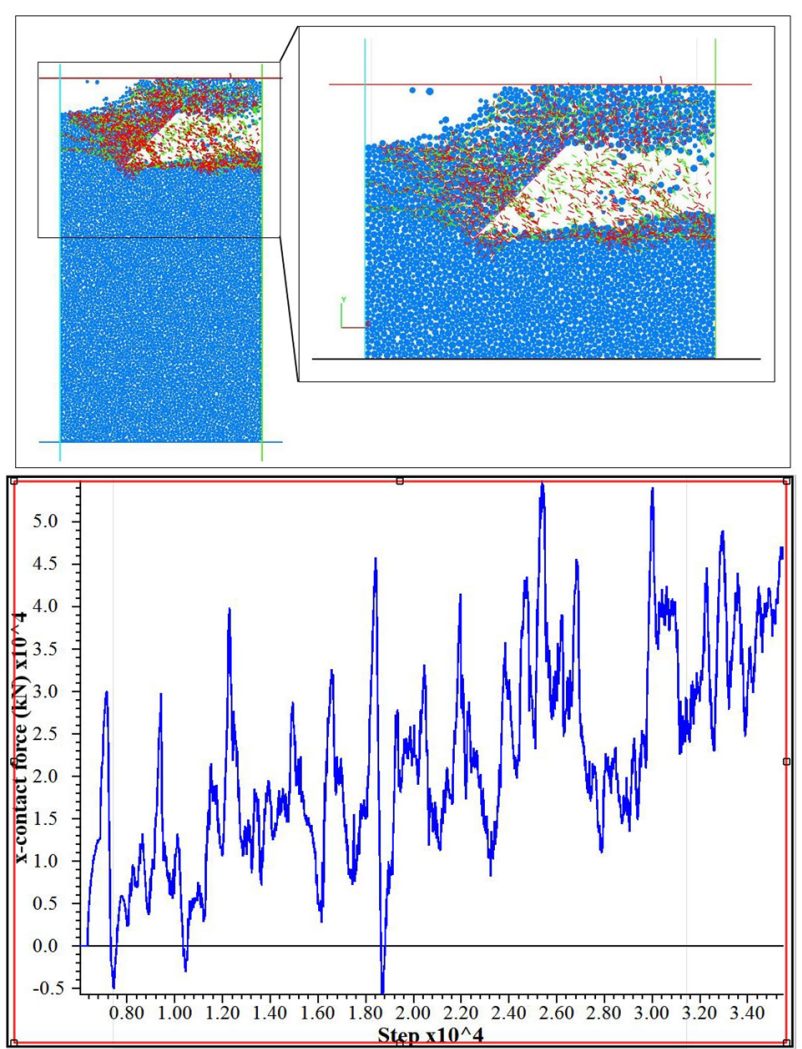

(a)

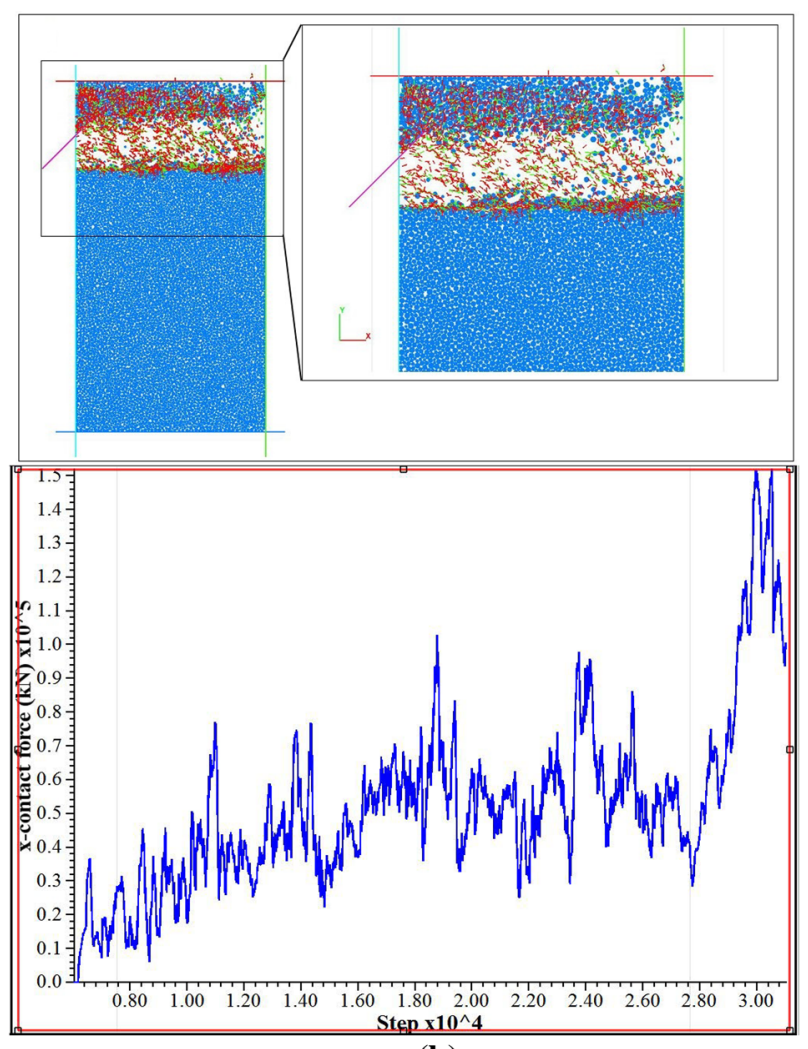

(b)

Fig. 13 Results of plow model with zero-degree angle: a Model 13, b Model 14

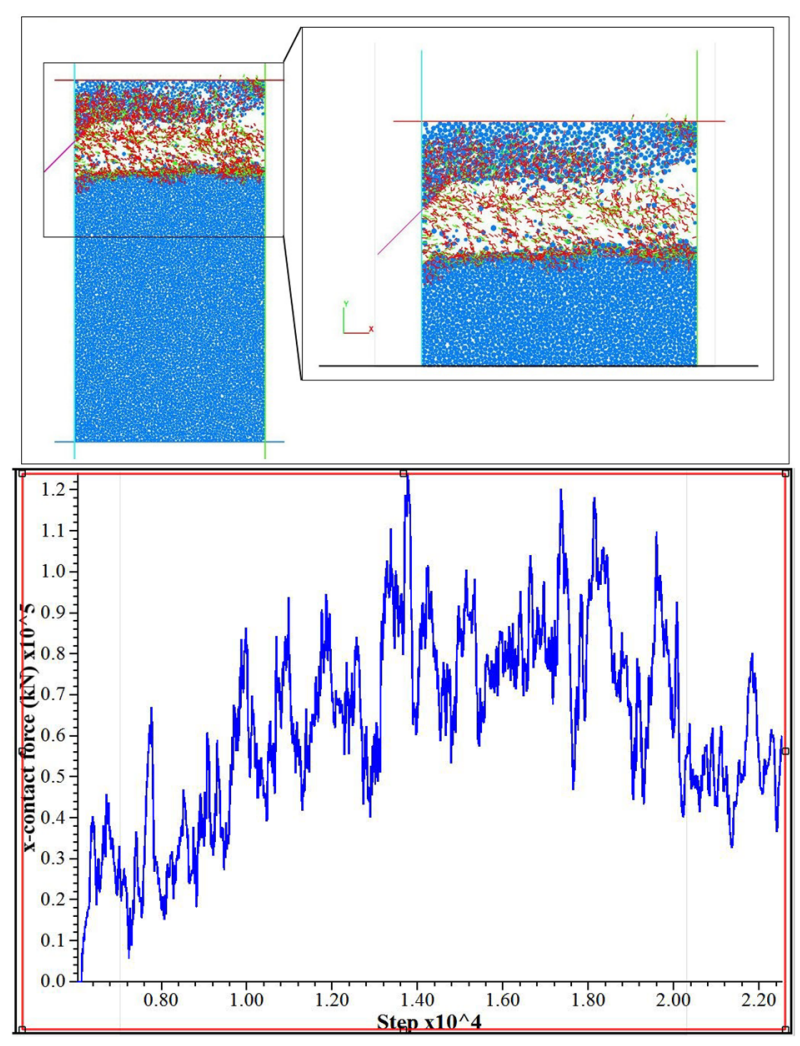

(a)
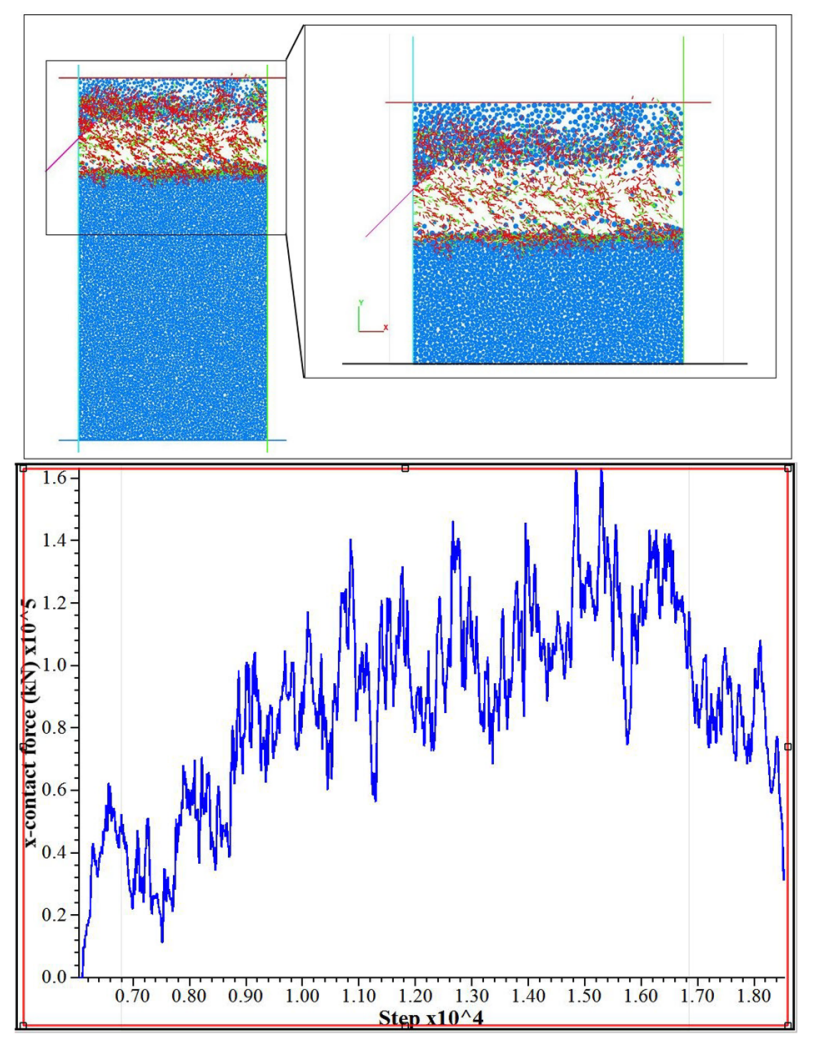

(b)

Fig. 14 Results of plow model with zero-degree angle: a Model 15, b Model 16 


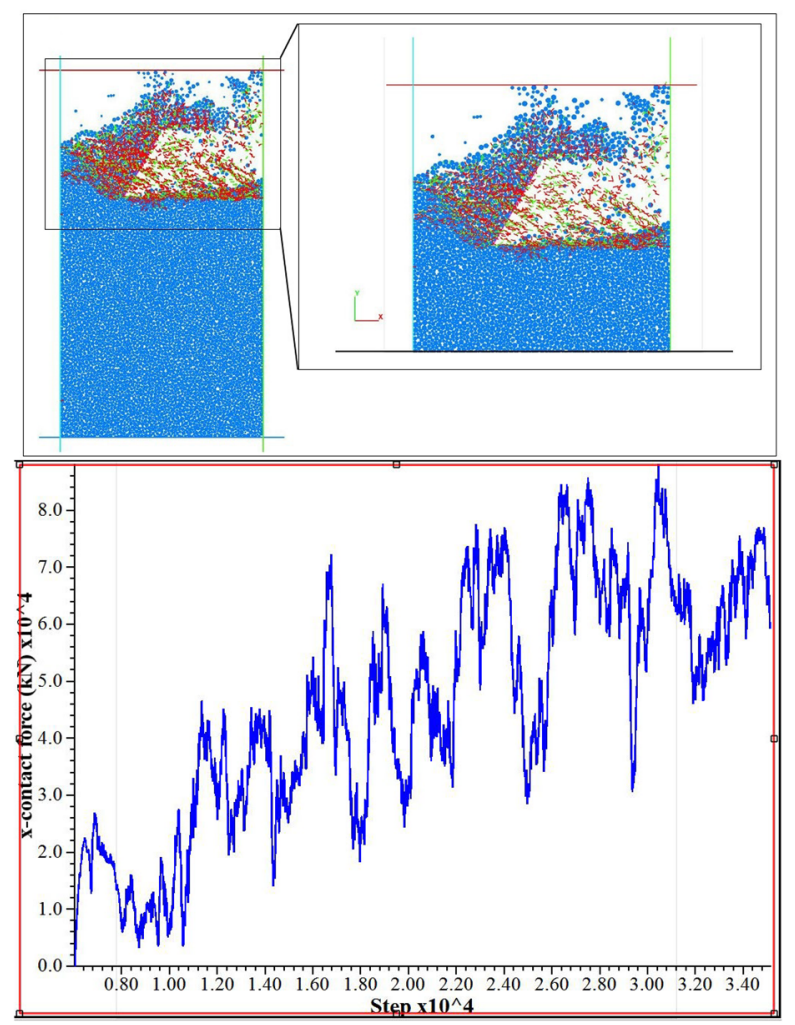

(a)

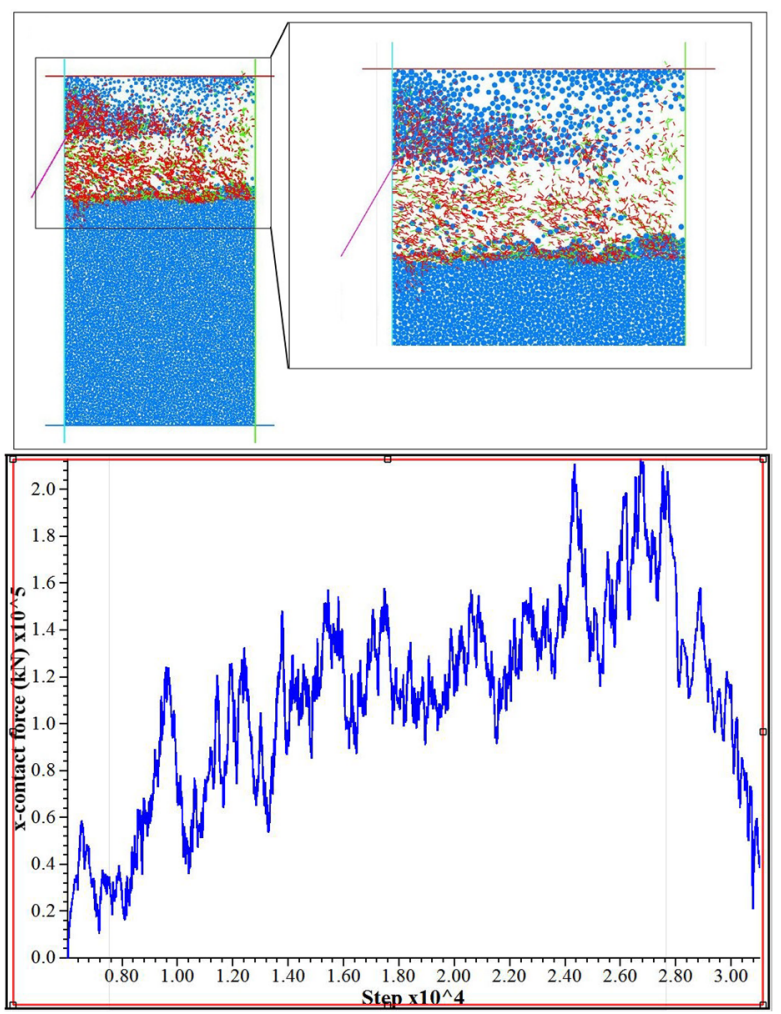

(b)

Fig. 15 Results of plow model with zero-degree angle: a Model 17, b Model 18

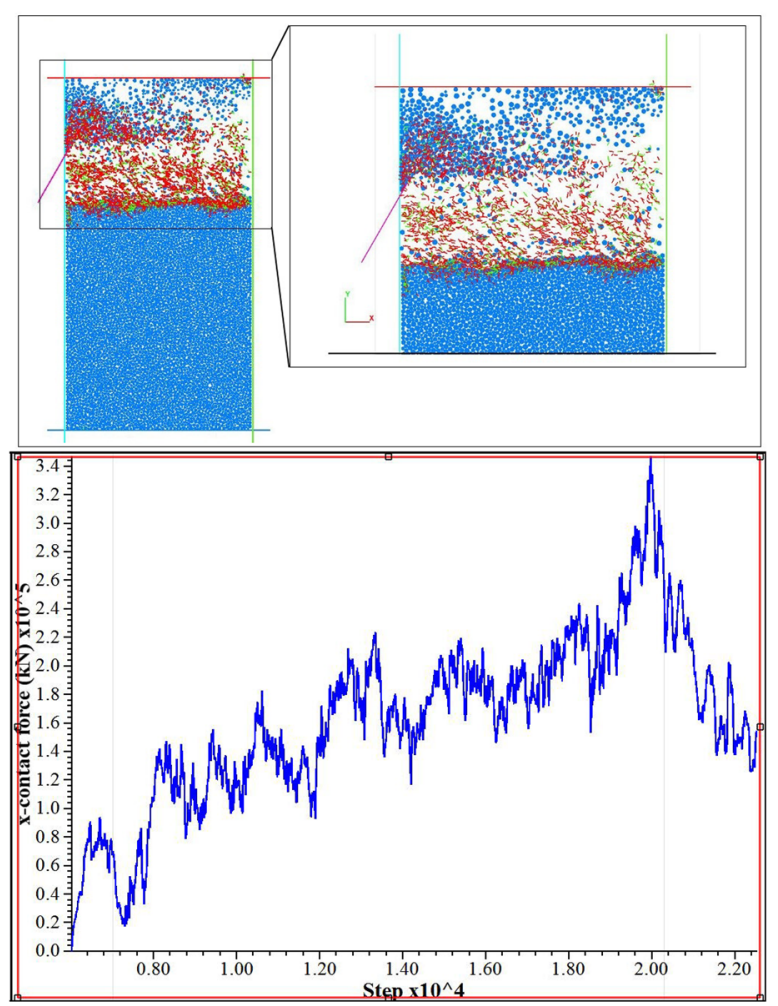

(a)
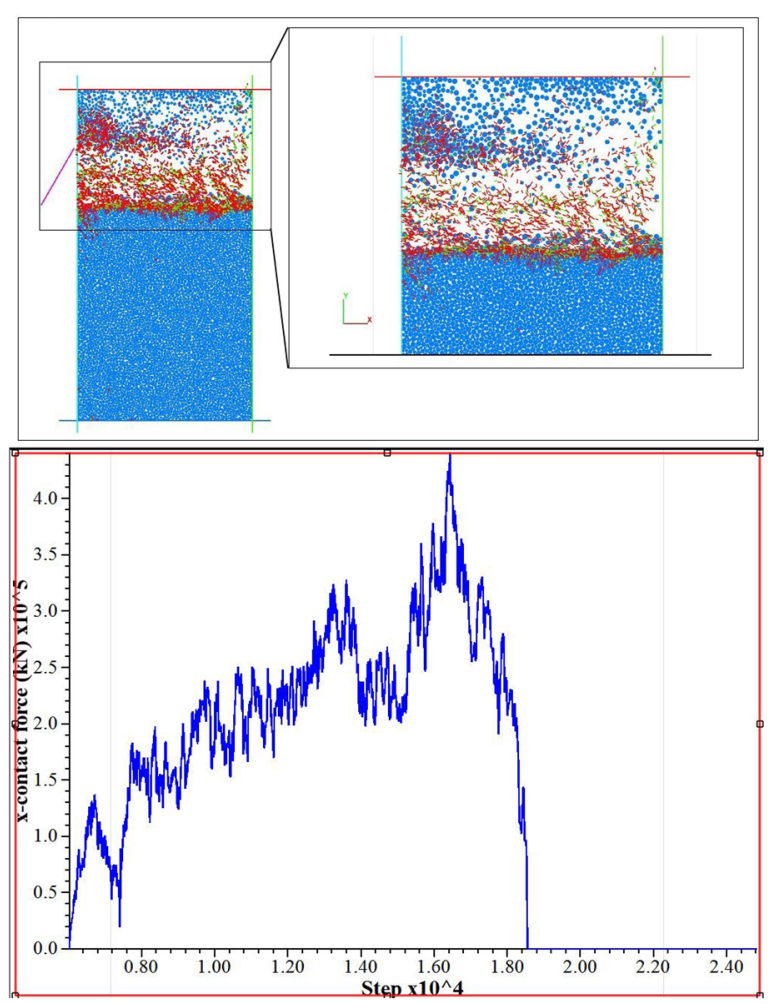

(b)

Fig. 16 Results of plow model with zero-degree angle: a Model 19, b Model 20 

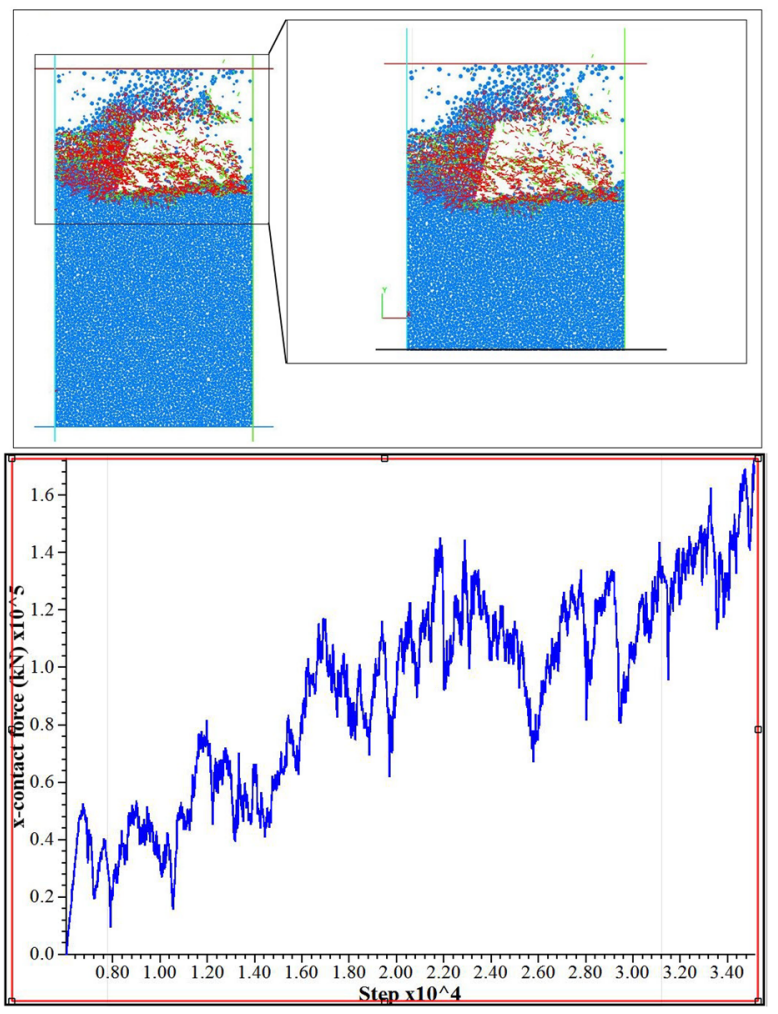

(a)

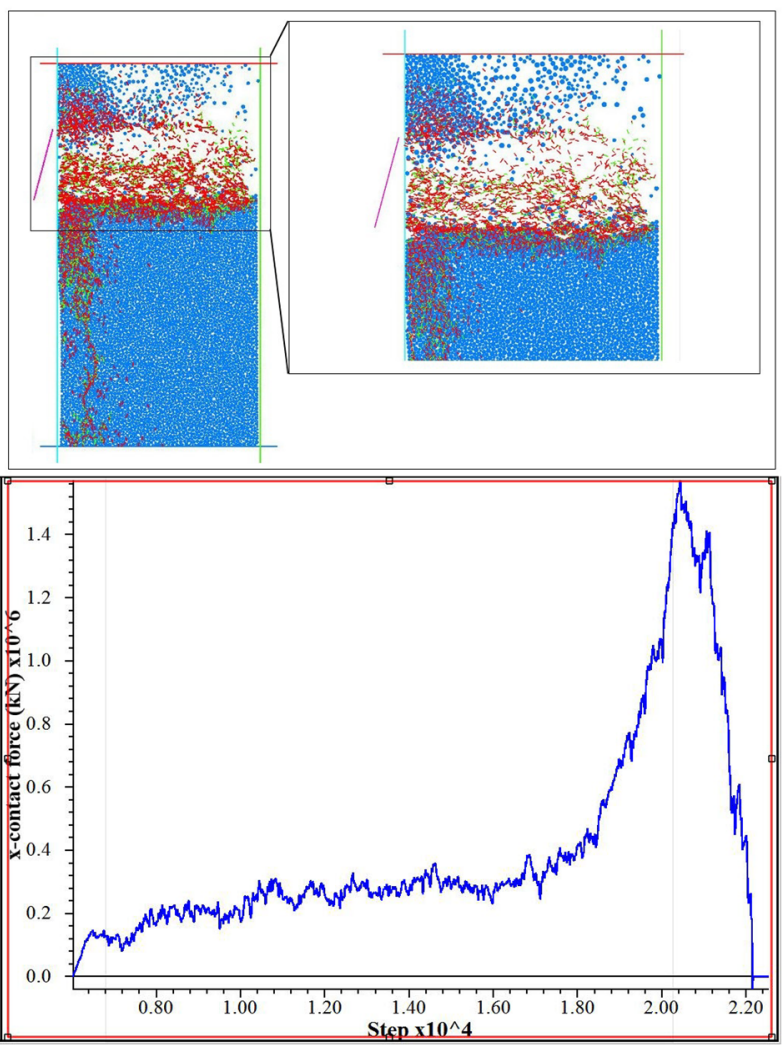

(a)
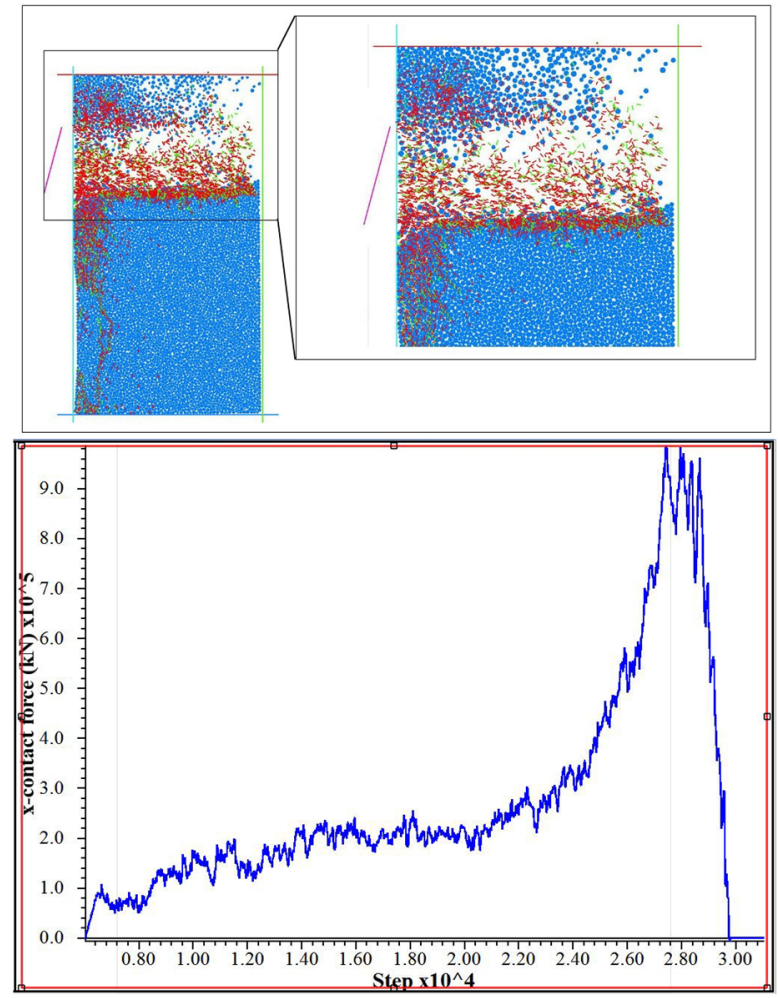

(b)
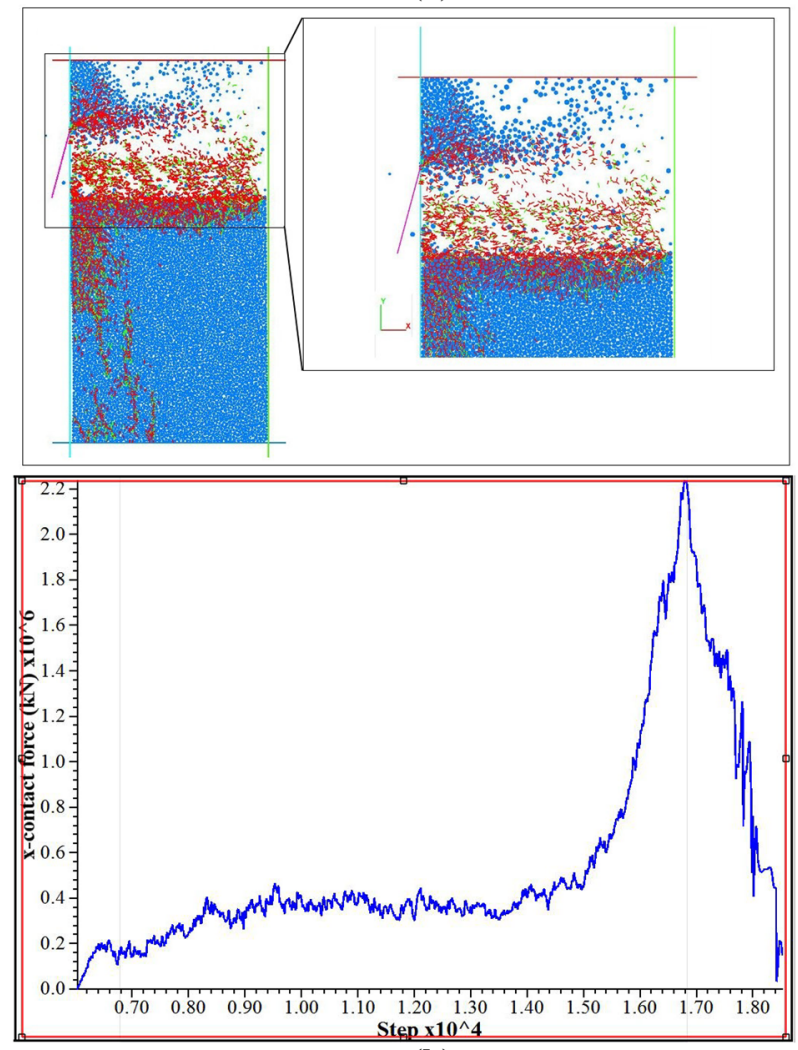

(b)

Fig. 17 Results of plow model with zero-degree angle: a Model 21, b Model 22

Fig. 18 Results of plow model with zero-degree angle: a Model 23, b Model 24 


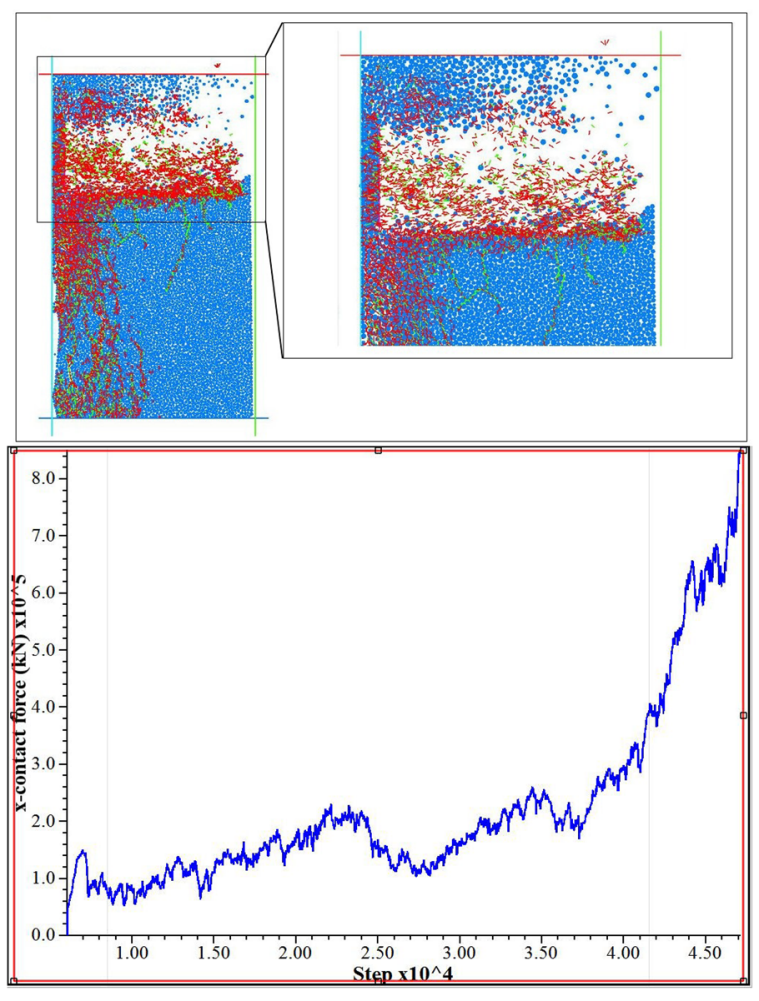

(a)
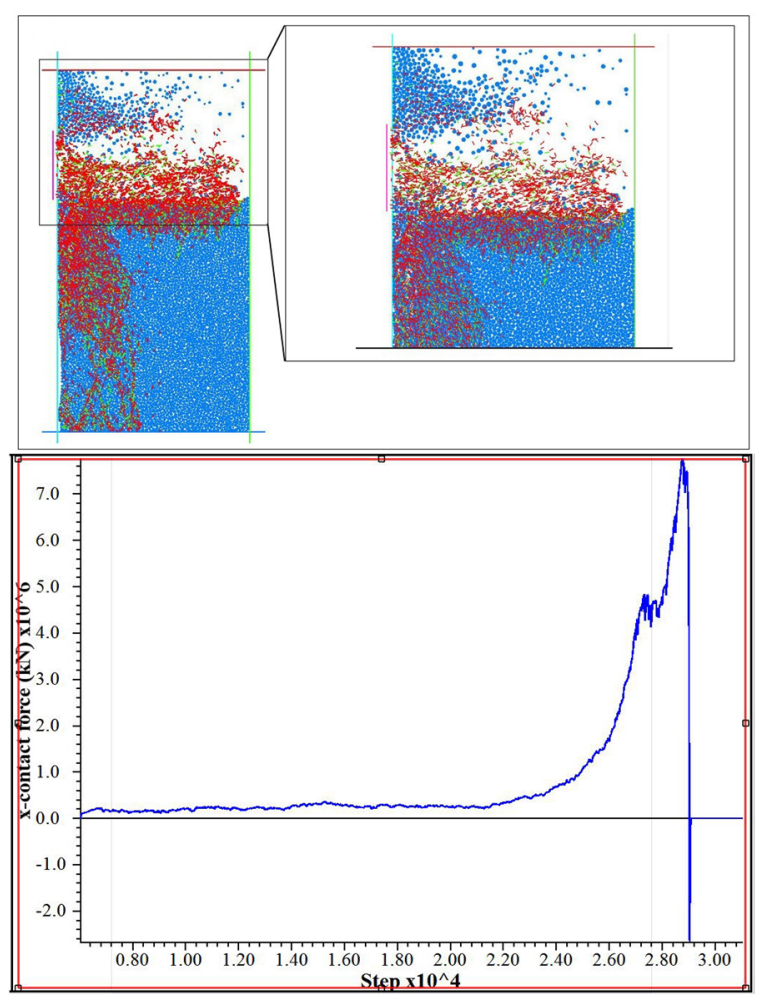

(b)

Fig. 19 Results of plow model with zero-degree angle: a Model 25, b Model 26
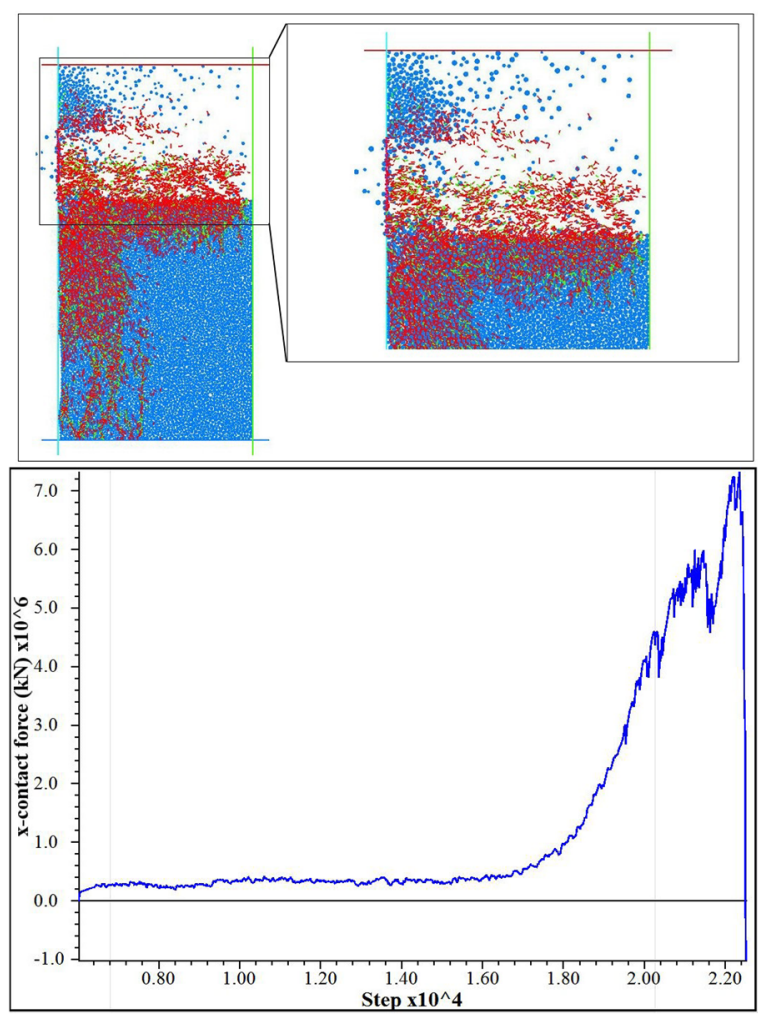

(a)
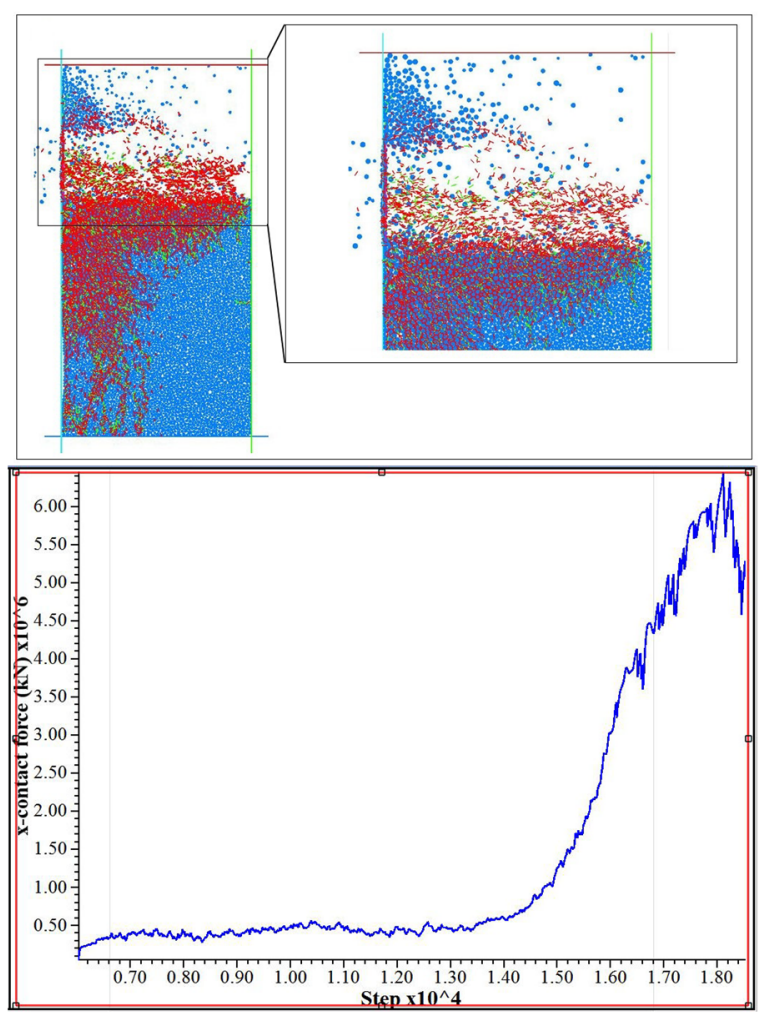

(b)

Fig. 20 Results of plow model with zero-degree angle: a Model 27, b Model 28 


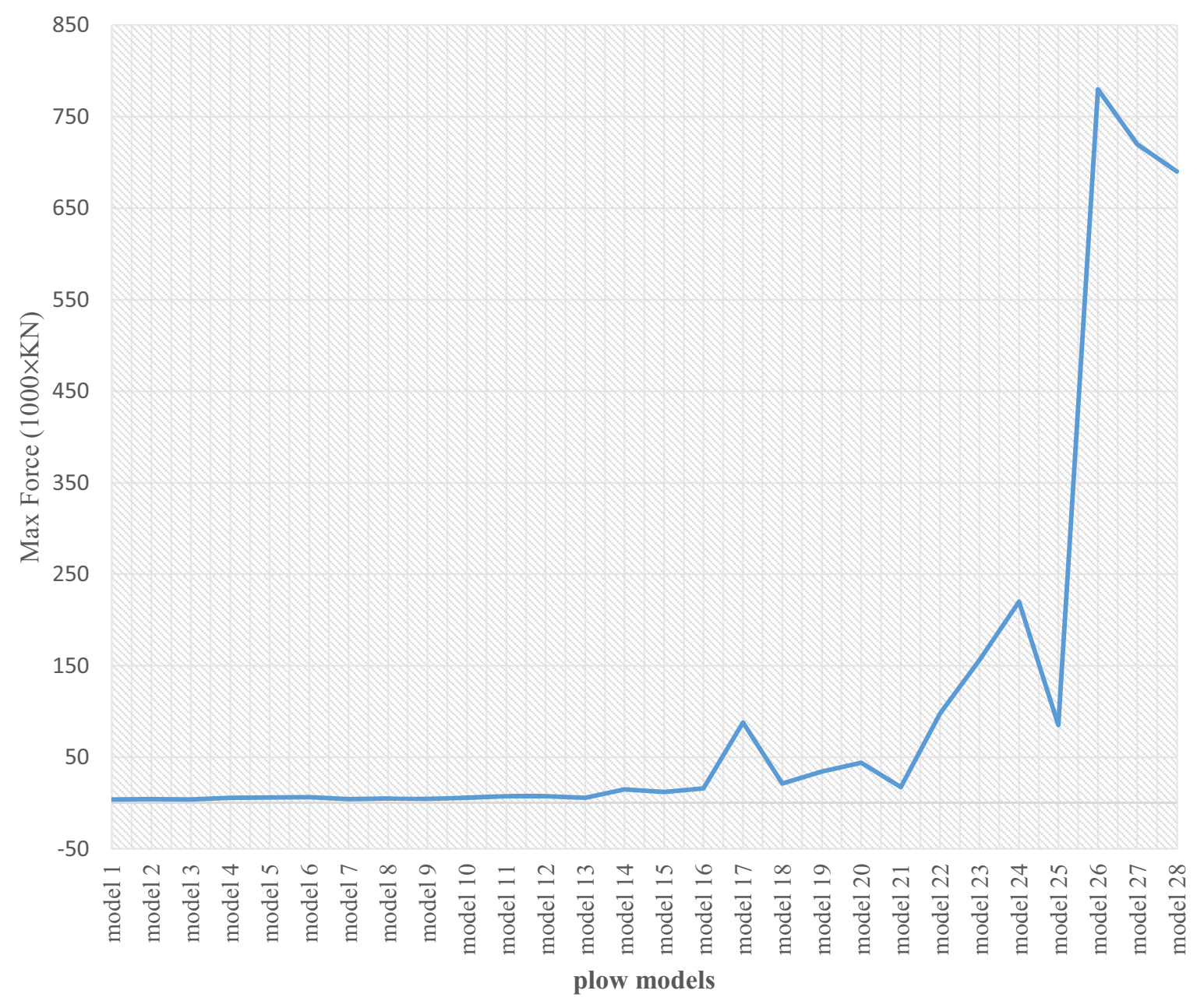

Fig. 21 Diagram of variations in maximum force applied to plow

model 21 is the best with the maximum force of 172,000 $\mathrm{kN}$.

The results of the plow model with a $90^{\circ}$ angle at the velocities of 3 and $6 \mathrm{~mm} / \mathrm{min}$ are presented in Fig. 19, and the results of the plow model with the velocities of 9 and $12 \mathrm{~mm} / \mathrm{min}$ are shown in Fig. 20.

In the models 25 to 28 , the increase in the force can be seen to be multiplied in respect to the $75^{\circ}$ angle. The model 25 is also the best model here.

The diagram presented in Fig. 21 shows the variation in the maximum force applied to the plow.

As shown in Fig. 21, in the plow models, the more the plow angle to the horizon, the more the applied force. Thus, the best model is for the plow with the lowest possible angle to the horizon, which the lowest point is zero here, and it was stated from the results of the previous sections that the best velocity in this model is $3(9 \mathrm{~mm} /$ $\mathrm{min}$ ), and the maximum force applied to the plow in the $X$ direction is $39,000 \mathrm{kN}$.

\section{Conclusion}

In this paper, the performance of the plow machine was modeled using the PFC software, which ultimately yielded the following results:

(1) By examining the results of plow modeling, a direct relationship may be obtained between the angle of plow and the maximum force applied to the plow.

(2) Increasing the maximum amount of force applied to the plow will increase the amount of consumed material (plow picks). This is not economically costeffective and technically increases the number of stopes in the cutting machine, which will result in the reduced production.

(3) Among the plow models at angles above $30^{\circ}$, the less the velocity, the lower the maximum force applied to the plow and the higher the applicability of the model.

(4) For the plow models with the angles less than $30^{\circ}$, the higher speeds can be mentioned as the better 
models, which will allow higher production to the mine management.

(5) For the high-angle models of the plow, the level of grinding and non-smooth cutting is increased, which may cause maintenance problems in the next steps. On the other hand, it also loosens the layer for the subsequent cuttings. However, the increased material grinding produces coal dust that causes many safety and health problems, and some limitations should be necessarily imposed to prevent this issue.

(6) The grinding and non-smoothness of the cutting surface for the lower plow angles are too less than that prevent maintenance and cause safety problems.

(7) The best model among the plow models is the one with the zero degree and $9 \mathrm{~mm} / \mathrm{min}$ velocity which has the lowest amount of maximum force applied to the plow and also the least amount of crack production.

Open Access This article is distributed under the terms of the Creative Commons Attribution 4.0 International License (http://crea tivecommons.org/licenses/by/4.0/), which permits unrestricted use, distribution, and reproduction in any medium, provided you give appropriate credit to the original author(s) and the source, provide a link to the Creative Commons license, and indicate if changes were made.

\section{References}

Ajamzadeh MR, Sarfarazi V, Haeri H, Dehghani H (2018) The effect of micro parameters of PFC software on the model calibration. Smart Struct Syst 22(6):643-662

Ataei M, Khalokakaei R, Hossieni M (2009) Determination of coal mine mechanization using fuzzy logic. Min Sci Technol 19(2):149-154

Bauckmann S, Myszkowski M (2011) Operational experiences with the plow system at the Pinnacle Mine in the USA. In: International mining forum conference, Poland

Chagowski M (2011) Power supply, control and automation systems of the high-performance plough systems based on the example of LW Bogdanka S.A. In: International mining forum conference, Poland

Cheng Y, Wang L, Liu H, Kong S, Yang Q, Zhu J, Tu Q (2015) Definition, theory, methods, and applications of the safe and efficient simultaneous extraction of coal and gas. Int J Coal Sci Technol 2(1):52-65

Choi SO, Lee SJ (2015) Three-dimensional numerical analysis of the rock-cutting behavior of a disc cutter using particle flow code. KSCE J Civil Eng 19(4):1129-1138

Fan L, Ma X (2018) A review on investigation of water-preserved coal mining in western China. Int $\mathrm{J}$ Coal Sci Technol 5(4):411-416

Haeri H, Sarfarazi V (2016) Numerical simulation of tensile failure of concrete using particle flow code (PFC). Comput Concr 18(1):39-51

Haeri H, Sarfarazi V, Hedayat A, Tabaroei A (2016) Effect of tensile strength of rock on tensile fracture toughness using experimental test and PFC2D simulation. J Min Sci 52(4):647-661
Hejmanowski R (2015) Modeling of time dependent subsidence for coal and ore deposits. Int J Coal Sci Technol 2(4):287-292

Ju Y, Zhu Y, Xie H, Nie X, Zhang Y, Lu C, Gao F (2019) Fluidized mining and in situ transformation of deep underground coal resources: a novel approach to ensuring safe, environmentally friendly, low-carbon, and clean utilisation. Int $\mathrm{J}$ Coal Sci Technol 6(2):184-196

Kurtobashev W (2011) Contemporary plow technology in Russia. In: International mining forum conference, Poland

Lee SJ, Choi SO (2011) Numerical analysis on cutting power of disc cutter with joint distribution patterns. J Korean Soc Rock Mech Tunn Undergr Sp 21(3):151-163

Lee SJ, Choi SO (2013) Three dimensional numerical analysis on rock cutting behavior of disc cutter using particle flow code. Tunn Undergr Sp 23(1):54-65

Matula J (2011) Experience with plow equipment at OKD. In: International mining forum conference, Poland

Merritt WJ (1989) Economics of thin seam plowing in the United States. In: Proceedings 1989 multinational conference on mine planning and design, Lexington, 23-26 May 1989. OES Publications, Lexington, pp 125-133

Moon T, Oh J (2012) A study of optimal rock-cutting conditions for hard rock TBM using the discrete element method. Rock Mech Rock Eng 45:837-849

Myszkowski M (2011) Efficiency optimization of plow systems through the precise planning of new and comprehensive enhancement of operating longwalls. In: International mining forum conference, Poland

Osterman W (1974) To plough or shear. A comparison is made of these two methods of mining, considering seam properties, equipment, rate of advance ect. GLUCKAUF 110(7):249-255 (In German)

Paschedag U (2011) Plow technology-history and today's state-ofthe-art. In: International mining forum conference, Poland

Philipp G (2011) Chains-boon or bane for modern plow technology?. In: International mining forum conference, Poland

Potyondy D (2015) Material-modeling support in PFC. Itasca Consuling Groupe, Inc., Minneapolis

Potyondy D, Cundall P (2004) A bonded-particle model for rock. Int J Rock Mech Min Sci Geomech Abstr 41:1329-1364

Sarfarazi V, Haeri H, Marji MF, Zhu Z (2017a) Fracture mechanism of Brazilian discs with multiple parallel notches using PFC2D. Periodica Polytech Civil Eng 61(4):653-663

Sarfarazi V, Haeri H, Shemirani AB (2017b) Shear behavior of nonpersistent joint under high normal load. Strength Mater 49(2):320-334

Smith JD (1972) A mathematical investigation into the optimum ratio of plough and conveyor speeds in multi-plough bidirectional cutting. Int J Rock Mech Min Sci 9:767-781

Stefanko R, Bise CJ (1983) Coal mining technology: theory and practice. SME-AIME, Littleton

Stopa Z (2011) Plough technique at LW bogdanka S.A.—present state and prospects of development. In: International mining forum conference, Poland

Sun JS (2011) Numerical simulation of influence factors for rock fragmentation by TBM cutters. Rock Soil Mech 32(6): 1891-1897

Tabas coal mine (1995) Geological report. Technical office. Geology division

Tang DX (2011) Operational experiences of automated plow systems in Tiefa, China. In: International mining forum conference, Poland

Tor A (2011) Past experience and further expectations with regard to application of plow technology at Jastrzębska Spółka Węglowa S.A. In: International mining forum conference, poland 
Voss HW (2011) Plough longwall operations under challenging geological conditions. In: International mining forum conference, Poland

Whittaker BN, Guppy GA (1970) High-speed ploughing with special reference to the fixed-cut principle. Int J Rock Mech Min Sci $7: 445-479$

Wirth P, Chang J, Syrbe RU, Wende W, Hu T (2018) Green infrastructure: a planning concept for the urban transformation of former coal-mining cities. Int J Coal Sci Technol 5(1):78-91
Yang SQ, Tian WL, Huang YH (2018) Failure mechanical behavior of pre-holed granite specimens after elevated temperature treatment by particle flow code. Geothermics 72:124-137

Zhuravlev YN, Porokhnov AN (2019) Computer simulation of coal organic mass structure and its sorption properties. Int J Coal Sci Technol. https://doi.org/10.1007/s40789-019-0256-3 